\title{
Evaluation of Sample Taxicab Security Cameras
}

\author{
Shengke Zeng*, Harlan E. Amandus, Alfred A. Amendola, Richard S. Current, \\ Bradley H. Newbraugh, Douglas M. Cantis, Darlene Weaver \\ Division of Safety Research, National Institute for Occupational Safety and Health, Morgantown, WV, USA \\ Email: *szeng@cdc.gov
}

How to cite this paper: Zeng, S., Amandus, H.E., Amendola, A.A., Current, R.S., Newbraugh, B.H., Cantis, D.M. and Weaver, D. (2017) Evaluation of Sample Taxicab Security Cameras. Journal of Transportation Technologies, 7, 390-422.

https://doi.org/10.4236/jtts.2017.74026

Received: March 3, 2017

Accepted: October 9, 2017

Published: October 12, 2017

Copyright $\odot 2017$ by authors and Scientific Research Publishing Inc. This work is licensed under the Creative Commons Attribution International License (CC BY 4.0).

http://creativecommons.org/licenses/by/4.0/

\begin{abstract}
Background: Taxicab drivers have high homicide rates compared to all worker occupations. To help taxi fleets select effective taxicab security cameras, this project tested eight sample taxicab security cameras for determining their photographic quality which correlated to the effectiveness of in-taxicab facial identification. Methods: Five photographic quality metric thresholds: 1) resolution, 2) highlight dynamic range, 3) shadow dynamic range, 4) lens distortion, and 5) shutter speed, were employed to evaluate the photographic quality of the sample cameras. Waterproof tests and fire-resistive tests on recording memory cards were conducted to determine the memory card survivability in water and simulated fire. Results: The Full-HD $(1920 \times 1080$ pixels $)$, HD $(1280 \times 720$ pixels $)$ and dual-lens VGA $(2 \times 640 \times 480$ pixels with wide-angle and telephoto lenses) cameras performed well in resolution tests in daylight conditions. The resolution of a single-lens VGA $(640 \times 480$ pixels $)$ camera did not meet the resolution minimum requirements. All of the recording memory cards passed the five-meter/72-hour waterproof test. A fire resistant chamber made with one fire insulation material could protect a single memory card at $538^{\circ} \mathrm{C} / 1000^{\circ} \mathrm{F}$ for a five-minute simulated fire test. Conclusions: Single-lens VGA-resolution $(640 \times 480$ pixels $)$ cameras are not suggested for use as security cameras in taxicabs with two or more rows of seats. The recording memory cards can survive 5-meter/72-hour waterproof tests. The memory card chamber built with an existing heat insulation material can protect an individual memory card during $538^{\circ} \mathrm{C}\left(1000^{\circ} \mathrm{F}\right) / 5$-minute fire resistance oven-test.
\end{abstract}

\section{Keywords}

Taxicab Homicide, Facial Identification, Taxicab Security Camera Tests, Resolution, Dynamic Range, Lens Distortion, Shutter Speed, Recording Media Protection 


\section{Introduction}

Workplace violence has consistently been a leading cause of workplace fatalities and injuries since national occupational health surveillance efforts began at the National Institute for Occupational Safety and Health (NIOSH) in 1980 [1]. The latest data available from the Bureau of Labor Statistics reveals that in 2014 there were 409 workplace homicides, making workplace homicides the fourth leading cause of work-related fatalities [2]. There were 31 homicide fatalities in the Taxi and Limousine Sector in 2014 [2]. Taxicab drivers, within the transportation industry, have the highest homicide rates among all industries (10 per 100,000 workers in 2014), 35 times greater than that among all workers $(0.28$ per 100,000 workers in 2014) [3].

To improve taxicab driver safety, many cities have installed equipment to help reduce crimes against taxicab drivers, including taxicab partitions and taxicab security cameras. In recent years, the latter intervention-security cameras-have become a popular alternative. Some cities have already installed security cameras in their taxicabs as a deterrent for crimes against taxicab drivers [4]. NIOSH has completed epidemiologic studies that suggest taxicab security camera systems are highly effective in reducing taxicab driver fatalities [4]. The studies showed that the cities with taxicab cameras experienced a threefold reduction in taxicab driver homicides compared with control cities. However, there is no peer-reviewed published literature to evaluate the technical effectiveness of current taxicab security camera models in use in the U.S. for taxicab customer facial identifications. Also, there is no national taxicab camera selection guidance in the US. Only a few domestic and international cities have issued local taxicab camera regulations or guidance [5]-[11], or study reports on taxicab crime reduction after taxicab security camera installation [12] [13].

A NIOSH research engineering project, entitled "Taxicab Security Camera System Evaluation Study", was developed in response to a request by the International Association of Transportation Regulators (IATR). The project conducted a series of camera tests in various in-taxicab light and seat conditions to (1) determine the minimum technical requirements for an effective security camera system in taxicab facial identification in Phase I of the project and (2) evaluate market-available sample taxicab security cameras with the minimum technical requirements as the metric thresholds for Phase II of the project. Phase I developed five photographic minimum quality metrics for evaluating in-taxicab performance of a taxicab security camera: 1) photograph resolution, 2) highlight dynamic range, 3) shadow dynamic range, 4) lens distortion and 5) shutter speed [14]. An in-cab facial photograph taken by a security camera, with the quality at or above the metric thresholds, may contain sufficient facial information to allow customer identification, if necessary. In order to help transportation regulators and taxi fleets select effective taxicab security camera systems, Phase II evaluated eight sample taxicab security cameras (either market-available or pre-market) to determine how the photographic quality of the sample cameras correlated to the effectiveness of in-cab customer facial identifi- 
cations. Two specially designed test charts inside a simulated taxicab were photographed by each of the eight sample cameras in various light and seat conditions. The camera quality metric information was retrieved from the captured images by photographic quality measurement software. The quality metric data were compared with the proposed metric quality thresholds which were developed in Phase I.

This paper describes Phase II of the project. The objectives of the current study were to: 1) evaluate the in-taxicab performance of eight sample taxicab security camera systems using the previously determined technical minimum requirements as the quality metric thresholds; and 2) test the durability of the memory cards for maintaining the recorded images in adverse events. The image recording memory cards were evaluated for: 1) the survivability of image recording memory cards in water; and 2) the effectiveness of fire insulation chambers for protecting image recording memory cards during simulated taxicab fires.

\section{Methods/Procedures}

\subsection{Overview of Taxicab Security Camera Evaluation}

Minimum Requirements for Taxicab Security Cameras. To comprehensively assess a taxicab security camera's photographic ability, the study in Phase I determined the thresholds of five minimum photographic quality requirements. These requirements were used as the technical quality metrics to evaluate the photographic quality of a taxicab security camera which correlates to the effectiveness of in-cab facial identification [14]. The study quantified the thresholds of these five metrics under four extreme taxicab light conditions and in three cab-seat positions. These thresholds, which were developed in Phase I, are shown in Table 1. More details regarding the methods and results of Phase I of the project are available in Zeng et al. [14]. The dynamic range and lens distortion thresholds in the table were re-measured by photographic quality test software Imatest Master (Imatest LLC, Boulder, CO), so that these thresholds would be compatible with the sample camera test results which were also measured by Imatest Master.

In Table 1, the four extreme light test conditions (measured in-cab) were: 1 ) L1-daylight (1000 - 7000 lux (light intensity unit: lumen/m²)), 2) L2-dark (0 - 2 lux, with infrared radiation), 3) L3-dark with backlight (illuminated by an automobile's headlights through the rear window, 2 - 400 lux, with infrared radiation) and 4) L4-sunset with sunrays through rear window (400 - 8000 lux). The thresholds for color images were only effective in L1 and L4 conditions, and the thresholds for black and white (B \& W) images were effective in all four light conditions. The three cab-seat positions were: 1) front-right (copilot seat), 2) rear-right and 3) rear-middle seats.

Camera Resolution. The camera resolution was measured by "line-widths per head height (LPHH)" in this study to normalize the captured facial image resolution of a customer sitting in either a front seat or back seat. When the camera 
resolution was measured in Project Phase I study, the head height was defined as $30 \mathrm{~cm}$, in order to include different human subject head heights in the photographic test charts $(22.0-26.4 \mathrm{~cm})$. In order to simulate a generalized human head in the camera tests, the head height of a $99^{\text {th }}$ percentile male $(25.5 \mathrm{~cm})$ in Phase II was defined as the head height in camera resolution measurements [15]. Subsequently, each of the 18 resolution thresholds in Table 1 should be normalized using the following formula:

$$
\text { Normalized Re solutionThreshold }=\text { Voted Re solutionThreshold } \times \frac{25.5 \mathrm{~cm}}{30 \mathrm{~cm}} .
$$

The image resolution was measured by Imatest Master. The median resolution threshold is $47.7 \mathrm{LPHH}$.

Camera Dynamic Range. Camera dynamic range in highlight (DRH) measures the ability of a taxicab camera to detect highlight details in a captured image in bright light condition. Camera dynamic range in shadow (DRS) measures the ability of a taxicab camera to detect shadow details in a captured image in twilight light conditions [16] [17]. The dynamic range can be observed on a standard Kodak Q-14 gray scale with 20 gray step patches (Eastman Kodak Company, Rochester, NY) in the captured taxicab test image. The light density difference between two adjacent gray steps is $1 / 3$ Exposure Value (EV).

Table 1. Summary of metric thresholds in four lights and three cab seats.

\begin{tabular}{|c|c|c|c|c|c|c|c|c|}
\hline Seat & Metric ${ }^{* *}$ & Unit & $\begin{array}{c}\text { Daylight } \\
\text { (L1)/ } \\
\text { (Color) }\end{array}$ & $\begin{array}{c}\text { Daylight } \\
\text { (L1)/ } \\
\text { (B \& W) }\end{array}$ & $\begin{array}{c}\text { Dark } \\
(\mathrm{L} 2) / \\
(\mathrm{B} \& \mathrm{~W})\end{array}$ & $\begin{array}{c}\text { Dark-BL } \\
\text { (L3)/ } \\
(\text { B \& W) }\end{array}$ & $\begin{array}{c}\text { Sunset-RW } \\
\text { (L4)/ } \\
\text { (Color) }\end{array}$ & $\begin{array}{c}\text { Sunset-RW } \\
\text { (L4)/ } \\
\text { (B \& W) }\end{array}$ \\
\hline \multirow{4}{*}{ Rear-Middle } & Resolution & $\begin{array}{l}\text { Line-Widths per } \\
\text { Head Height }\end{array}$ & 61.8 & 59.2 & 75.0 & 40.3 & 44.9 & 47.3 \\
\hline & $\begin{array}{c}\text { Dynamic Range, } \\
\text { Highlight }\end{array}$ & $\begin{array}{l}\text { Merged Gray } \\
\text { Steps }\end{array}$ & 5.7 & 4.6 & 4.2 & 3.3 & 5.5 & 5.7 \\
\hline & $\begin{array}{c}\text { Dynamic Range, } \\
\text { Shadow }\end{array}$ & $\begin{array}{c}\text { Recognizable Gray } \\
\text { Steps }\end{array}$ & 13.8 & 16.8 & 13.2 & - & - & - \\
\hline & Shutter Speed & Milliseconds & 33.3 & 36.7 & 33.3 & 33.3 & 33.3 & 33.3 \\
\hline \multirow{3}{*}{ Rear-Right } & Resolution & $\begin{array}{l}\text { Line-Widths per } \\
\text { Head Height }\end{array}$ & 47.7 & 47.1 & 46.8 & 42.2 & 45.7 & 74.0 \\
\hline & $\begin{array}{c}\text { Dynamic Range, } \\
\text { Highlight }\end{array}$ & Merged Gray Steps & 6.3 & 5.3 & 3.2 & 4.2 & 6.2 & 4.2 \\
\hline & $\begin{array}{l}\text { Dynamic Range, } \\
\text { Shadow }\end{array}$ & $\begin{array}{c}\text { Recognizable Gray } \\
\text { Steps }\end{array}$ & 12.6 & 18.0 & 17.3 & - & - & - \\
\hline \multirow{4}{*}{ Front-Right } & Resolution & $\begin{array}{l}\text { Line-Widths per } \\
\text { Head Height }\end{array}$ & 47.8 & 52.4 & 51.8 & 62.0 & 48.6 & 39.5 \\
\hline & $\begin{array}{c}\text { Dynamic Range, } \\
\text { Highlight }\end{array}$ & Merged Gray Steps & 5.1 & 4.3 & 4.8 & 4.2 & 4.8 & 3.3 \\
\hline & $\begin{array}{l}\text { Dynamic Range, } \\
\text { Shadow }\end{array}$ & $\begin{array}{c}\text { Recognizable Gray } \\
\text { Steps }\end{array}$ & 12.1 & $15.0^{*}$ & 16.3 & - & - & - \\
\hline & $\begin{array}{c}\text { Lens } \\
\text { Distortion }\end{array}$ & $\%$ & 24.4 & 24.4 & 24.4 & 24.4 & 24.4 & 24.4 \\
\hline
\end{tabular}

*Unable to measure the shadow dynamic range thresholds by Imatest software due to vulnerable image light conditions. Substituted with the median of 8 measureable shadow dynamic range thresholds. ${ }^{* *}$ Resolution thresholds were normalized with the height of a 99 th percentile human head $(25.5 \mathrm{~cm})$. Dynamic range thresholds and lens distortion thresholds were re-measured by Imatest software. 
In highlight condition, a taxicab camera with less DRH can detect more highlight detail, and observe less washed out and merged gray steps on the captured Q-14 gray scale image, and vice versa. The unit of the DRH thresholds used here was the "number of merged gray steps". In twilight conditions, a taxicab camera with more DRS can detect more twilight details, and observe more recognizable gray steps on the captured Q-14 gray scale image, and vice versa. The unit of the DRS thresholds used here was the "number of recognizable gray steps". The photographic dynamic range in this study was measured by Imatest Master. Since the light conditions with backlights (L3 and L4) could cause uneven light distribution and deteriorate the DRS measurements, the DRS thresholds in these light conditions were omitted in Table 1. The median DRH threshold is 4.7 merged gray steps, and the median DRS threshold is 15.0 recognizable gray steps.

Camera Lens Distortion. The percentage of lens distortion was measured by Imatest Master. Since the images captured in the front seats have more severe lens distortion than that in rear seats, it is unnecessary to measure lens distortion in rear seats. Only the front seat lens distortion thresholds are shown in Table 1. The lens distortion median threshold is $24.4 \%$.

Camera Shutter Speed. Due to equipment setup difficulties in the rear-right and front-right seats, the shutter speed thresholds were not measured in these seats. Table 1 shows the shutter speed thresholds only in rear-middle seat. The median shutter speed threshold is $33.3 \mathrm{~ms}$.

\subsection{Experimental Setup for Sample Camera Evaluation}

The taxicab security camera evaluation was conducted in a simulated taxicab with artificial lighting gear which simulated four extreme light conditions L1, L2, L3 and L4, as shown in Figure 1 and Figure 2. During evaluation tests, each of the eight sample cameras was mounted on a tripod standing in front of the central console near the rear-view mirror. The camera under test, which was aimed to the rear-middle seat, photographed two specially designed test charts for measuring the minimum photographic requirement metrics. A rectangular test chart, which measured camera resolution, dynamic range and lens distortion, was mounted on the head rest of each of the mentioned three seats, one at a time. A circular rotating test chart, which measured the camera shutter speed, was mounted in the rear-left (driver's side) seat.

Rectangular Test Chart. The rectangular test chart was photographed during sample camera evaluations for determining camera resolution, dynamic range and lens distortion, as shown in Figure 3. There was a slanted square on the right-hand side of the chart for measuring camera resolution by using the "Rescharts" module of Imatest Master. Camera resolution was determined by measuring the modulation transfer function (MTF) of the slanted square image using Imatest Master [18]. In post-test data analyses, the software measures the MTF of the slanted edge in the captured images. The photographic resolution of a camera is defined as the spatial frequency as the measured MTF falls to 50\% from its peak. The unit of the camera resolution in Imatest Master is line-widths 
per picture height. $(\mathrm{LPHH}$, Head height $=25.5 \mathrm{~cm})$.

The 20-step Q-14 gray scale was on the top of the rectangular chart for the camera dynamic range measurement. The camera dynamic range was measured by using the "Stepchart" module of Imatest Master [19]. On the left-hand side of the chart there was a rectangle stripe for measuring the lens distortion using the "Distortion" module of Imatest Master [20]. Lens distortion is an optical aberration that causes straight lines to curve near the center or edges of an image. The distortion is worse in front-seat facial images than in rear-seat images, therefore, only the front-seat lens distortion was measured in post-test data analyses.

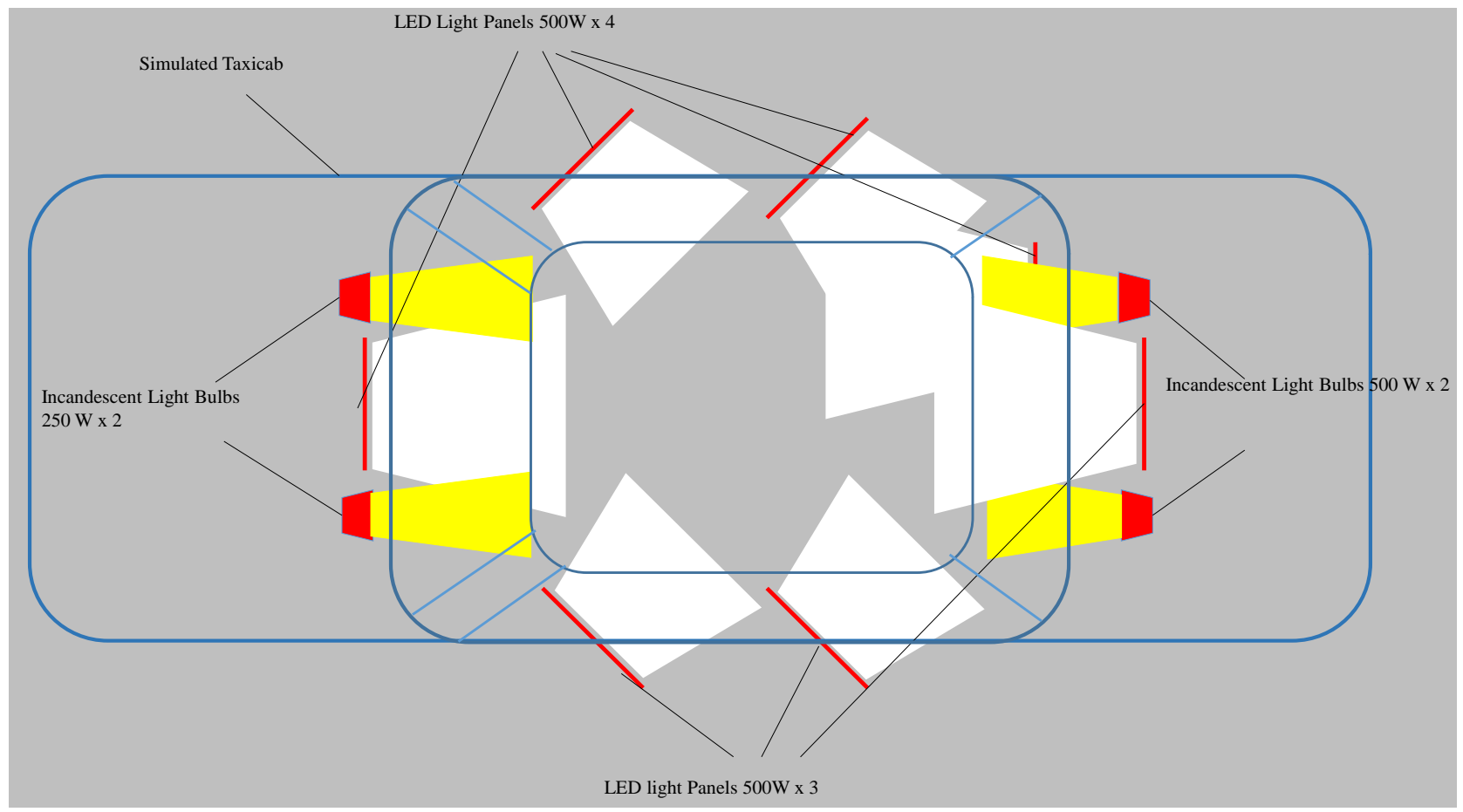

Figure 1. Reconstruction of light conditions in a simulated taxicab with seven white light emitting diode panels and four incandescent light bulbs.

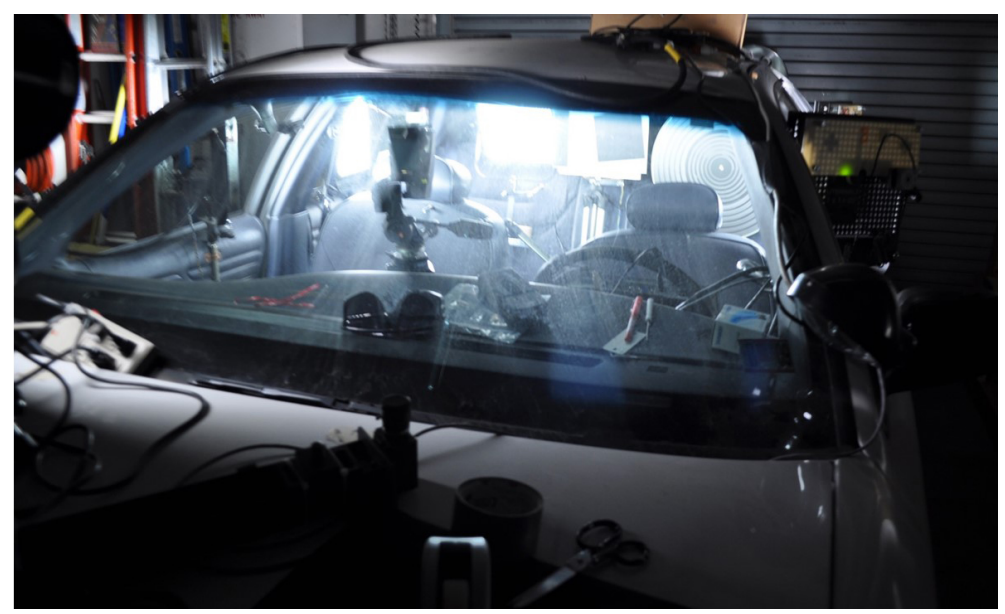

Figure 2. The simulated taxicab with white LED light panels and incandescent light bulbs. 


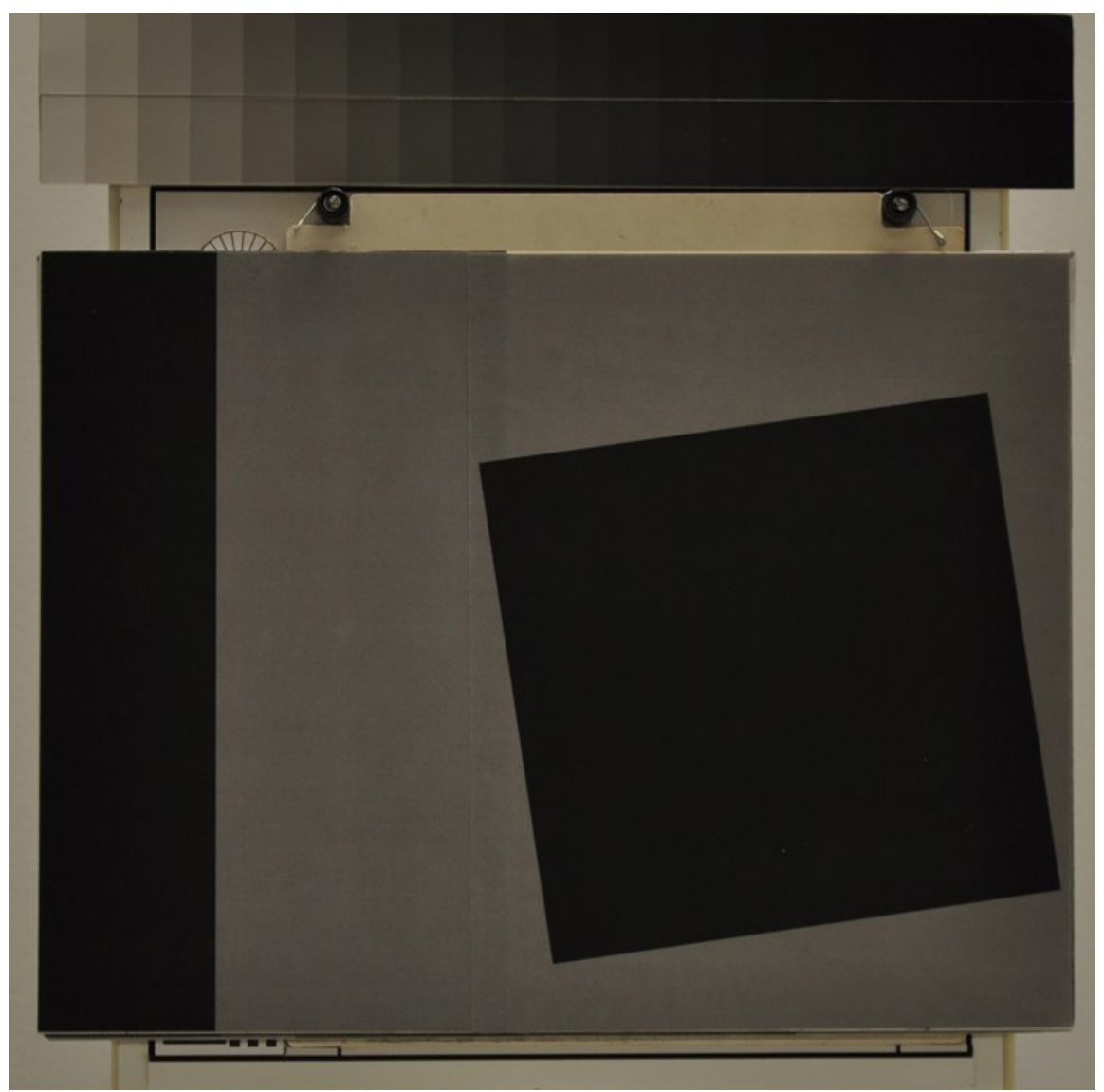

Figure 3. The test chart with a slanted square for camera resolution measurement, a vertical rectangle stripe for distortion measurement and a 20 -step gray scale for dynamic range measurement.

Circular Rotating Test Chart. The rotating circular test chart was used to measure the shutter speed of a sample camera under test (Figure 4). To accurately distinguish the shutter speed on the rotating test chart, the chart was rotating during the camera tests with a rim speed of $245.2 \mathrm{~cm} / \mathrm{second}$ [14]. On the test chart there were six blocks of white squares in the dark background for indication of six shutter speeds. In each block, there were three pairs of white squares. Each pair of the squares was at the same radius from the chart center, and the squares in each pair were separated with a separation angle. The separation angles in Block 1 to Block 6 were $11.2^{\circ}, 14.1^{\circ}, 18.7^{\circ}, 22.5^{\circ}, 28.1^{\circ}$ and $37.5^{\circ}$, respectively. As a sample camera captured an image of the rotating chart with a shutter speed of $1 / 50$ second, the chart rotated $11.2^{\circ}$ during the camera shutter opening. The blurred trace of each square on the photograph caused by $1 / 50$ second of shutter opening would be $11.2^{\circ}$ wide. The blurred traces of two squares in each of three pairs in Block 1 would merge since the two spots are separated $11.2^{\circ}$. The blurred traces of the square pairs in other blocks could not merge since they were separated with larger angles than $11.2^{\circ}$. In a similar way, Figure 5 illustrates different shutter speeds with nine rotating square merging patterns. 


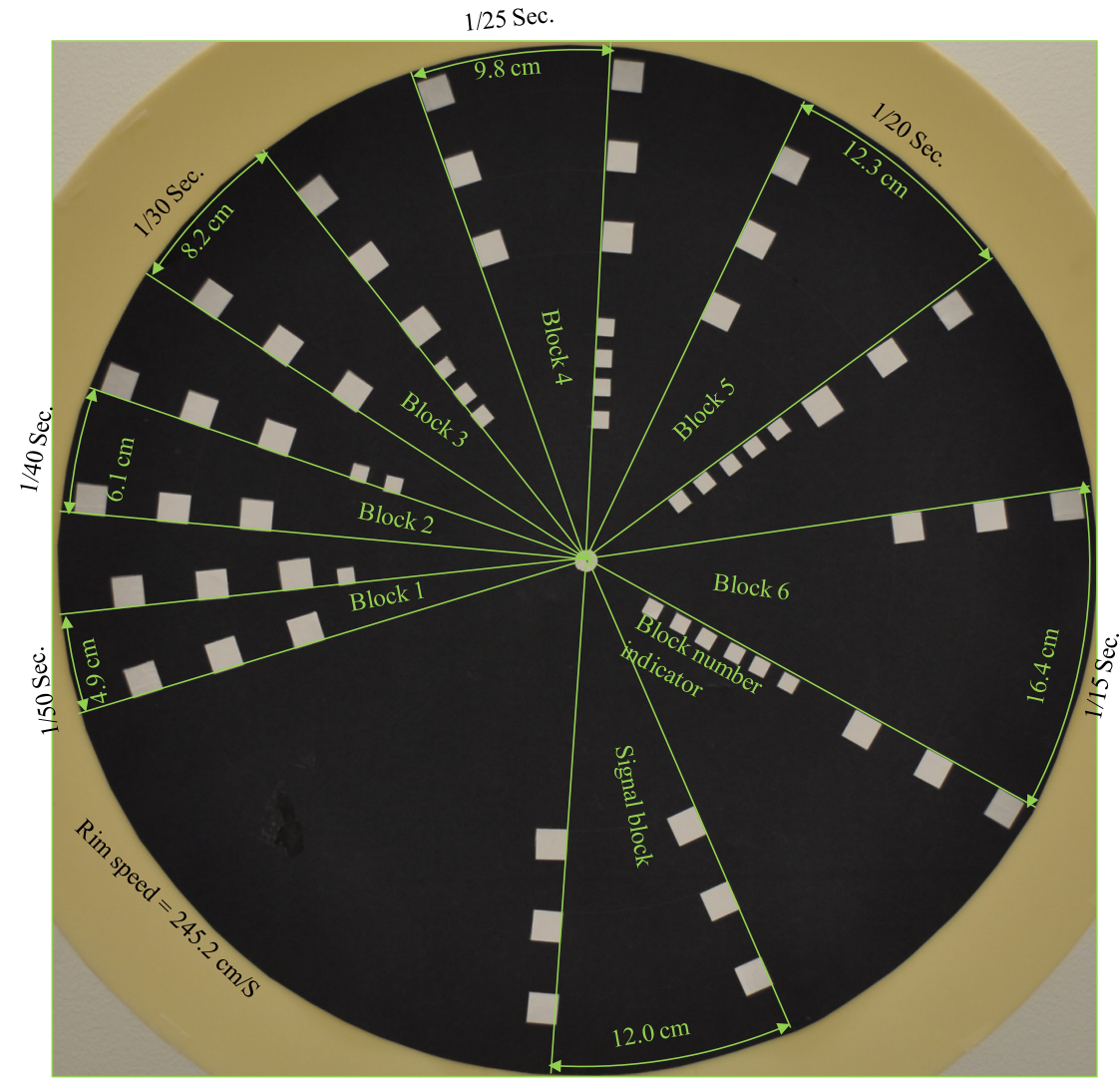

Figure 4. The rotating test chart rotates with the rim speed of $245.2 \mathrm{~cm} / \mathrm{S}$. There are seven shutter speed identification blocks: Blocks $1 \sim 6$ and Signal Block with three pairs of squares in each block. As the shutter speed decreases from 1/50 to $1 / 15$ second, the squares become blurred and merge in Blocks 1 to 6 sequentially.

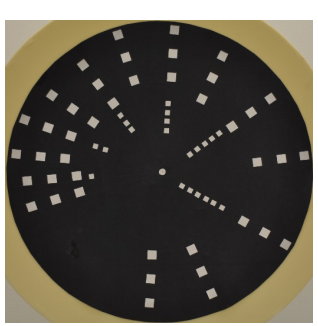

Still

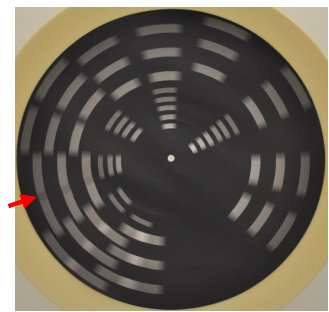

At $1 / 30 \mathrm{~S}$, squares in Block 3 merged.

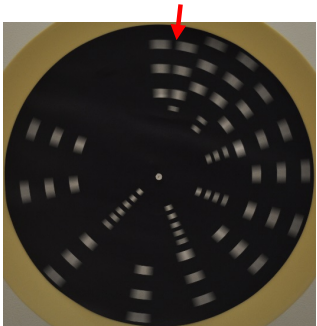

At $1 / 80 \mathrm{~S}$, squares in Block 1 were separate.

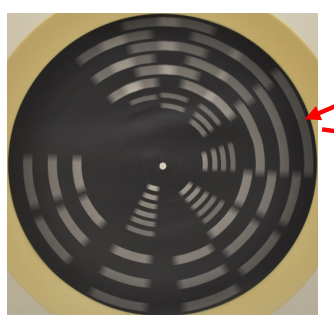

At 1/25 S, squares in Block 4 merged.

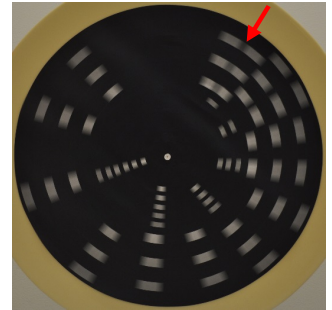

At $1 / 60 \mathrm{~S}$, squares in Block 1 were closer.

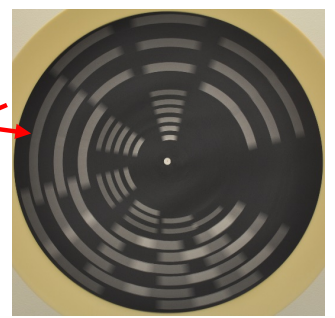

At $1 / 20 \mathrm{~S}$, squares in Block 5 merged.

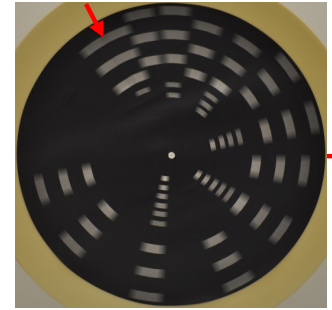

At $1 / 50 \mathrm{~S}$, squares in Block 1 merged.

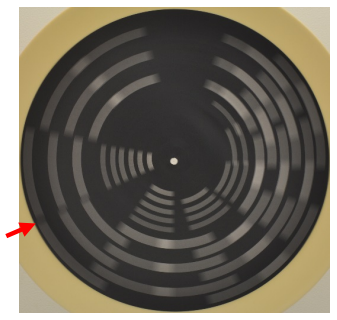

At 1/15 S, squares in Block 6 merged.

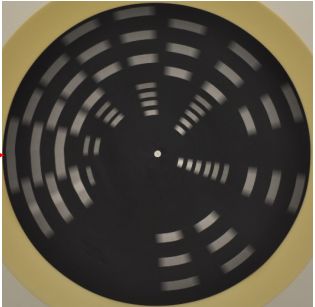

At $1 / 40 \mathrm{~S}$, squares in Block 2 merged.

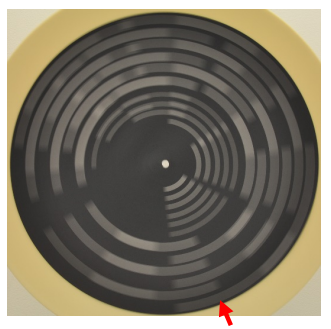

At $1 / 10 \mathrm{~S}$, squares in Block 6 intruded into Signal Block.

Figure 5. The rotating test chart on the left of the first row was still. The rest of nine charts rotated with the rim speed of 245.2 $\mathrm{cm} / \mathrm{S}$. The camera took nine photographs with nine different shutter speeds from $1 / 80$ to $1 / 10$ second. The blurred squares in Blocks $1 \sim 6$ merged sequentially as the shutter speed decreased. 


\subsection{Eight Sample Cameras under Test}

A total of eight sample taxicab security cameras $\mathrm{C} 1 \sim \mathrm{C} 8$, were evaluated in the simulated taxicab. Among the eight cameras, camera $\mathrm{C} 1$ had a full high definition (FHD) image sensor $(1920 \times 1080$ pixels). Camera C2 was a premarket camera with dual lenses and dual image sensors $(2 \times 720 \times 572$ pixels $)$. The camera had dual lenses with one wide-angle lens focused to the front-seat customer/driver, and one telephoto lens focused to the rear-seat customers. The camera was only available to the project for a limited time, and was only partially tested. Camera C3 was also a dual-lens and dual-image sensor $(2 \times 720 \times 572$ pixels $)$ camera with the left-lens focused to the left side of the cab and the right-lens focused to the right-side. Cameras C4, C5, C6 and C8 were common taxicab security cameras which had a single VGA $(640 \times 480$ pixels $)$ image sensor. Camera C7 had a high definition $(\mathrm{HD})$ image sensor $(1280 \times 720$ pixels). Each of the sample cameras captured at least five image frames in each combination of the four light conditions (L1 L4) and three seat positions (rear-middle, rear-right and front-right). The three best images from the five captured frames were selected to perform post-test data analyses using the software Imatest Master.

\subsection{Sample Camera Evaluation Procedures}

Capture Test Chart Images. One at a time, each of eight sample cameras, mounted near the rear-view mirror of the simulated taxicab, captured the images from the rectangular and rotating test charts which were placed in the cab-seats, as shown in Figure 6. The rectangular chart was mounted near the head rest of the front-right, rear-right and rear-middle seats, one seat at a time. The rotating chart was mounted on a specially designed chart stand in the rear-left seat, rotating at the rim speed of $245.2 \mathrm{~cm} / \mathrm{second}$. The test charts were illuminated by seven white Light Emitting Diode (LED) panels and four incandescent light bulbs to simulate four extreme light conditions (Figure 1).

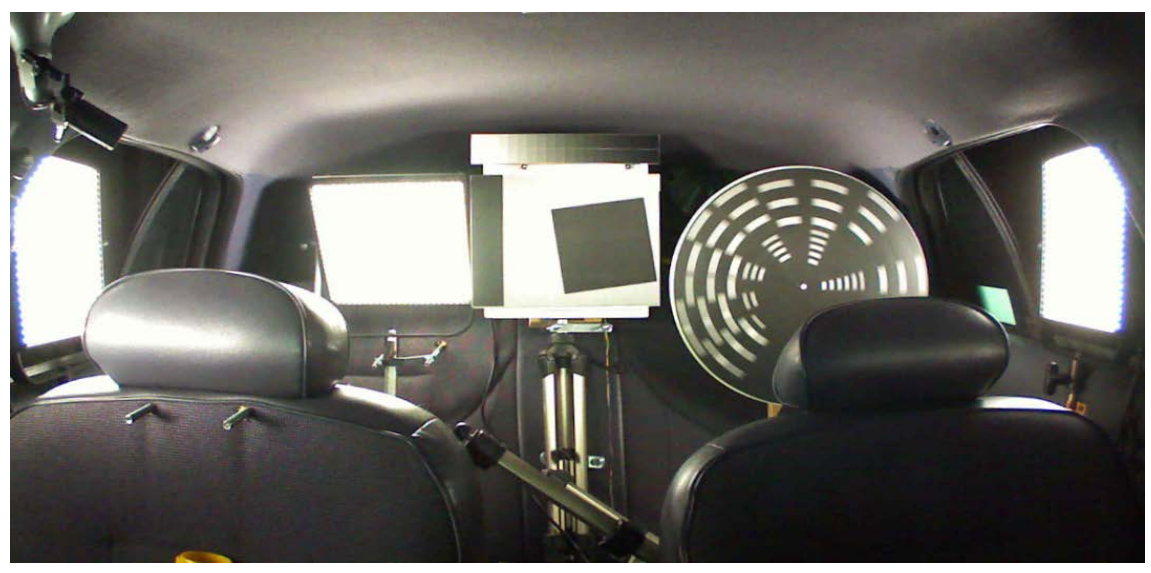

Figure 6. The sample camera test equipment setup. The rotating test chart was mounted in the rear-left seat. The rectangular test chart was mounted on rear-middle, rear-right and front-right seat, one at a time, while the camera under test captured cab images in each of these seat positions, and in four light conditions. 
Each camera captured a set of at least five frames of cab images, which contained the images of the two test charts, each time as the rectangular test chart moved among the three seat positions, and each time the cab-lighting gear switched among the four light conditions. Each of the sample cameras captured 12 sets of cab images in four light/three seat condition combinations. In each set of captured images, the three images with the best resolution and dynamic range were selected for post-test data analyses.

Measure Camera Resolution, Dynamic Range and Lens Distortion. In post-test data analyses the image quality test software Imatest Master analyzed the rectangular test chart in a captured cab image for camera resolution, dynamic range and distortion quality metrics, by using the "Reschart", "Stepchart", and "Distortion" modules of the software, respectively. During the camera resolution measurement, the cab image was rotated by the image editing software Microsoft Office "Image Manager" (Microsoft, Redmond, WA) until the rectangular test chart in the image was leveled. The rotated image was cropped with the height from the bottom of the Kodak Q-14 gray scale to the bottom of the rectangular test chart $(27 \mathrm{~cm})$. The resolution measurement module "Reschart" selected the cropped chart image and measured the MTF of the slanted square. The software defines the image resolution as the spatial frequency, where the MTF value falls $50 \%$ from its peak. This resolution was later converted to the resolution with the unit of line-widths per head height $(\mathrm{LPHH}$, Head Height $=$ $25.5 \mathrm{~cm}$ ) [15]. Figure 7 shows the resolution test charts. To compare different post-test image resolutions, three resolution result charts, which were output from Imatest "Rescharts" module, are shown. The resolution of the test chart images, captured by three cameras with different resolutions, was measured by "Rescharts" module. The lower-left plot of each result chart is the measured MTF function curve versus spatial frequency. The image resolution (MTH50P) is shown in the chart with the unit of "linewidth per picture height (LW/PH)". Since the picture height of the captured image is $27 \mathrm{~cm}$ and the head height of a 99th percentile male is $25.5 \mathrm{~cm}$, the test image resolution in LW/PH should be normalized as: Test image resolution $(\mathrm{LPHH})=\mathrm{MTF} 50 \mathrm{P}$ resolution $(\mathrm{LW} / \mathrm{PH}) /$ $27 \times 25.5$. The normalized resolutions of the three test images are: (a) 221.2 LPHH (highest resolution, above the resolution threshold); (b) $75.3 \mathrm{LPHH}$ (close to the resolution threshold (black and white) in dark condition in rear-middle seat); and (c) $6.4 \mathrm{LPHH}$ (minimum resolution, below any resolution threshold, unacceptable).

During camera dynamic range measurement, the leveled Kodak Q-14 gray scale image with 20 gray steps in the test chart was cropped from the cab image by Image Manager. The "Stepchart" module selected the gray scale as the region of interest (ROI) and measured the dynamic range of the image. In highlight dynamic range measurement, the "Stepchart" module selected gray steps 1 to 10 as the ROI and measured the number of recognizable gray steps on the left-hand side of the gray scale. The number of washed out and merged gray steps was calculated by 


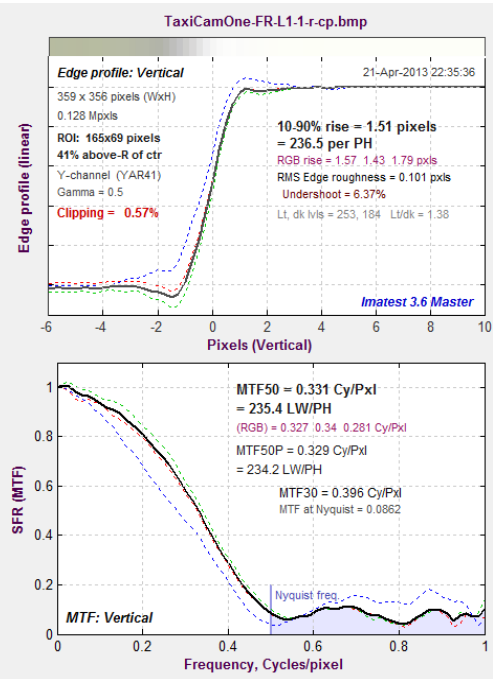

(a)

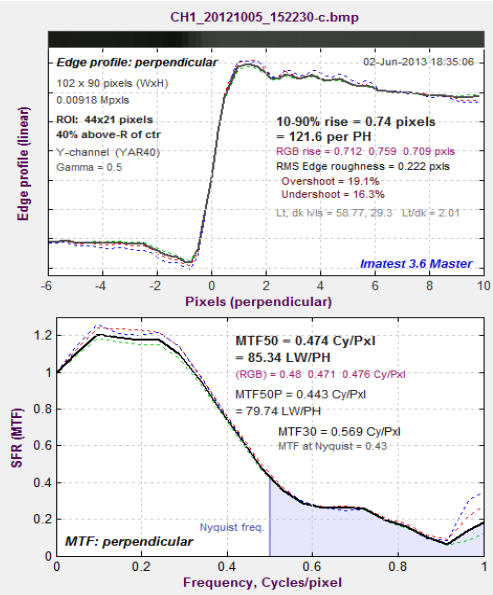

(b)
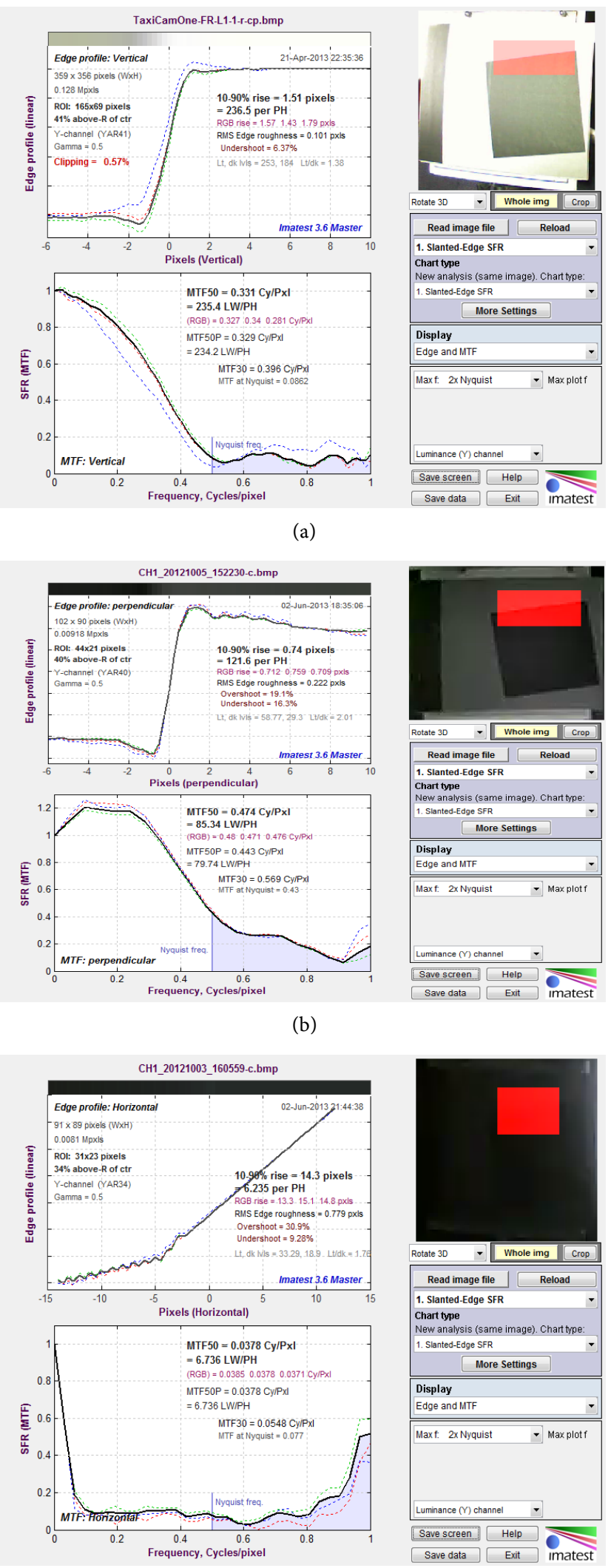

(c)

Figure 7. The camera resolution test charts before normalization: (a) 234.2 LPHH (highest resolution), (b) 79.7 LPHH (close to the threshold), and (c) 6.7 LPHH (unacceptable). 
subtracting the number of recognizable gray steps from 10. In shadow dynamic range measurement, the "Stepchart" module selected gray steps 1 to 20 as the ROI to determine the number of recognizable gray steps. Figure 8 shows the dynamic range testing charts which determined the highlight dynamic range of the images. To compare different highlight dynamic ranges of post-test images, three Kodak Q-14 gray scale images, captured by three cameras with different dynamic ranges, and the dynamic range result charts measured by "Stepchart" module, are shown. The number of gray steps detected is shown on the upper chart of each dynamic range result chart. The number of washed out and merged gray steps is calculated by subtracting the number of detected gray steps from 10 . The calculated washed out and merged gray steps are: (a) 8.2 (most merged gray steps, worse than any highlight dynamic range threshold, unacceptable), (b) 3.3 (on the highlight dynamic range threshold (black and white) in dark with backlight condition in the rear-middle seat) and (c) 0.23 (no merged gray steps, better than any highlight dynamic range threshold). Figure 9 shows the dynamic range testing charts which determined the shadow dynamic range of the images. To compare different shadow dynamic ranges of post-test images, three Kodak Q-14 gray scale images, captured by three cameras with different dynamic ranges, and the dynamic range result charts measured by "Stepchart" module, are shown. The number of gray steps detected, shown on the upper chart of each dynamic range result chart, is the number of recognizable gray steps. The shadow dynamic range of three post-test Kodak Q-14 gray scale images are: (a) 18.5 (most recognizable gray steps, better than any shadow dynamic range threshold); (b) 16.6 (close to the shadow dynamic range threshold (black and white) in dark condition and in rear-middle seat) and (c) 7.8 (least recognizable gray steps, worse than any shadow dynamic range threshold, unacceptable).

During lens distortion measurement the "Distortion" module of Imatest Master selected the vertical edge of the rectangle stripe in the rectangular test chart as the ROI and measured the distortion coefficient of the image in percentage. Figure 10 shows the test resulting distortion charts with different distortion coefficients.

Shutter Speed. The shutter speed of a camera under test was determined by examining the pattern of blurred square traces in the rotating test chart in the captured cab images (Figure 4 and Figure 5). The trace examination was started from 1/50 second block (Block 1) of the chart, and continued until the 1/15 second block (Block 6). If the square traces merged in a block, the camera shutter speed was equal or slower than the shutter speed that the block indicated. If the square traces were not merged in the block, the shutter speed was faster than the shutter speed of the block. Figure 11 shows the rotating chart patterns with three different camera shutter speeds.

\subsection{Recording Media Waterproof Test Procedures}

The recorded data stored on a flash memory card should not be damaged as the 


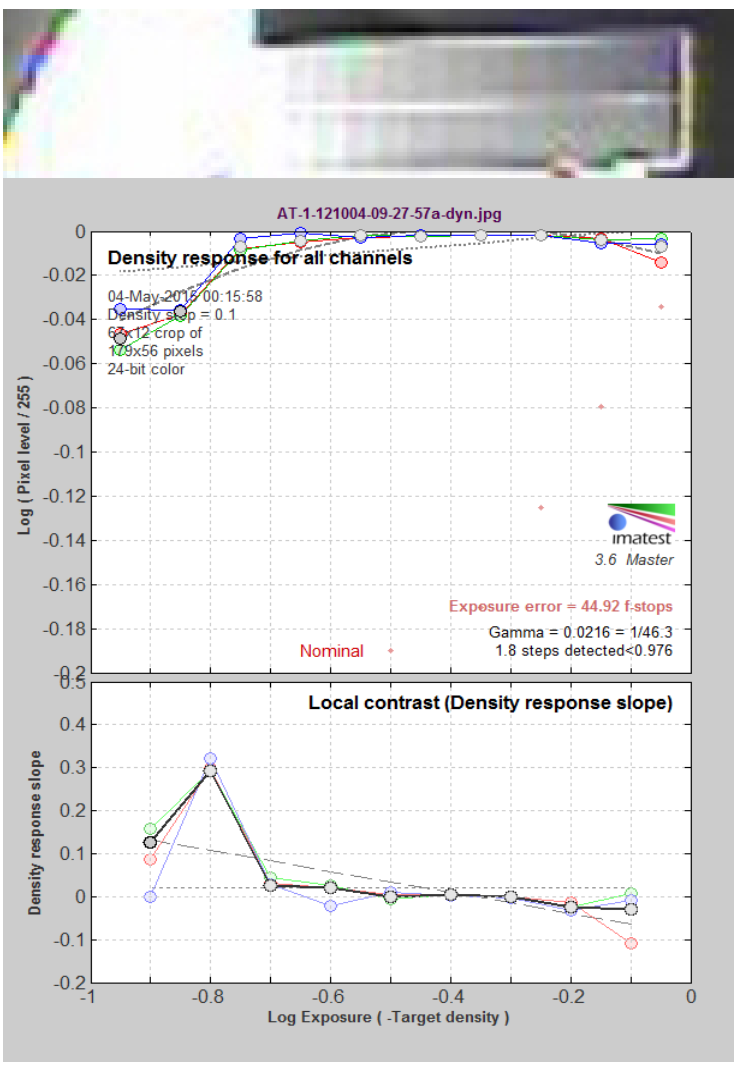

(a)
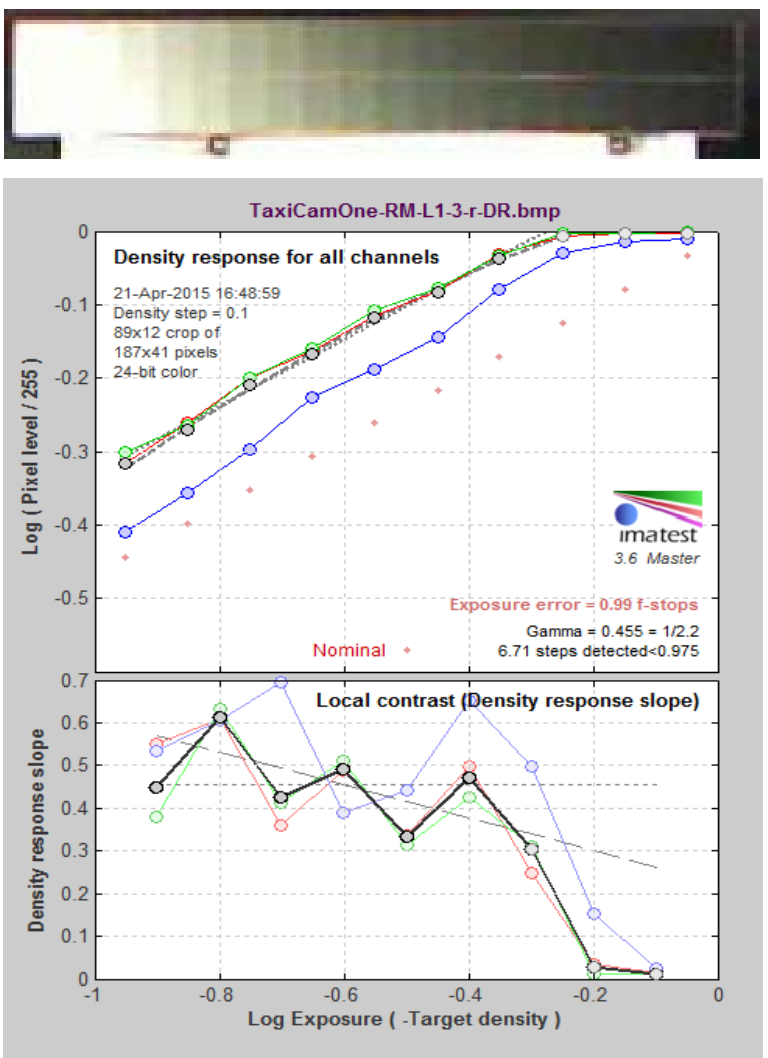

(b)

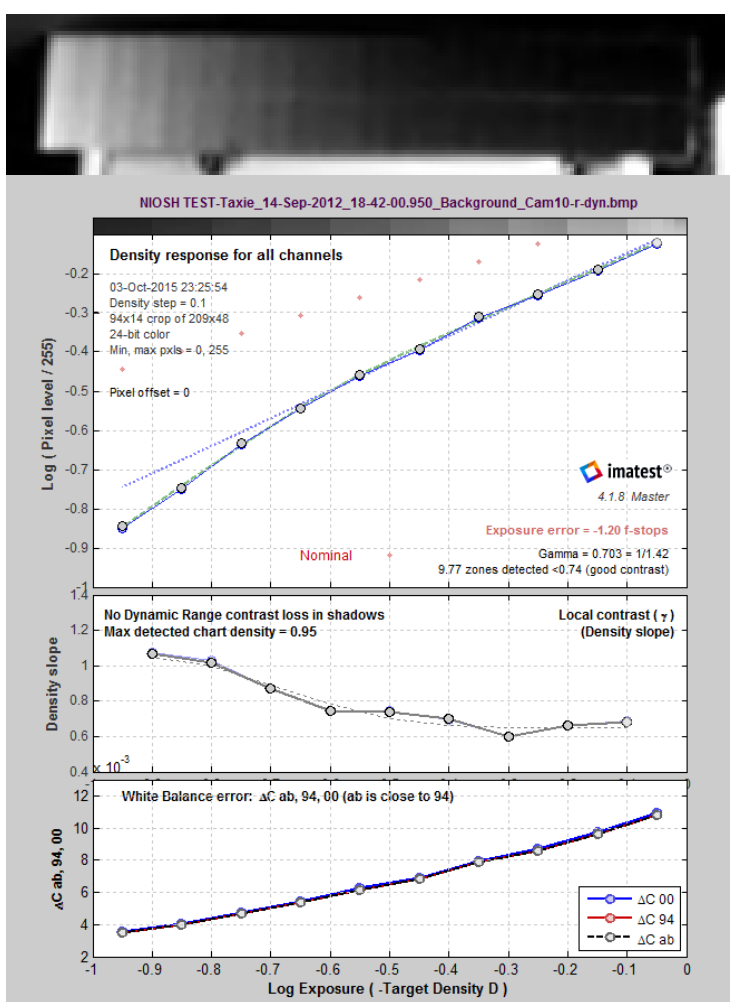

(c)

Figure 8. The camera highlight dynamic range test charts measured in merged gray steps: (a) 8.2 (unacceptable), (b) 3.3 (on the threshold), and (c) 0.23 (better than the threshold). 


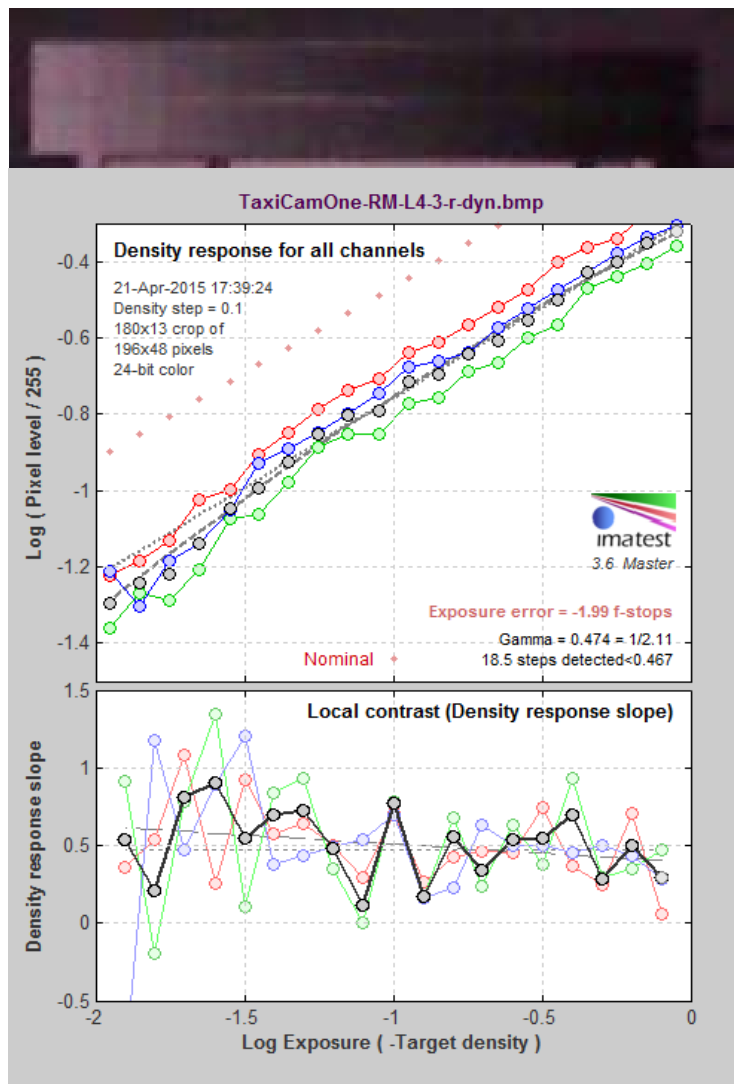

(a)

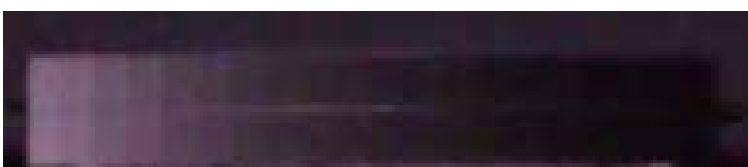

TaxiCamOne-RM-L5-2-r-dyn.bmp

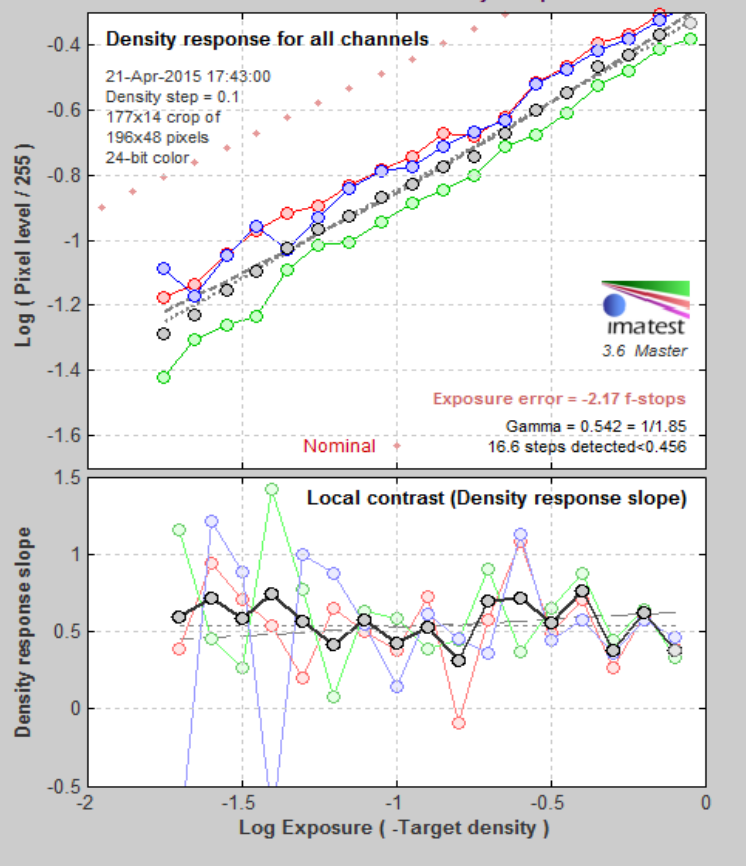

(b)
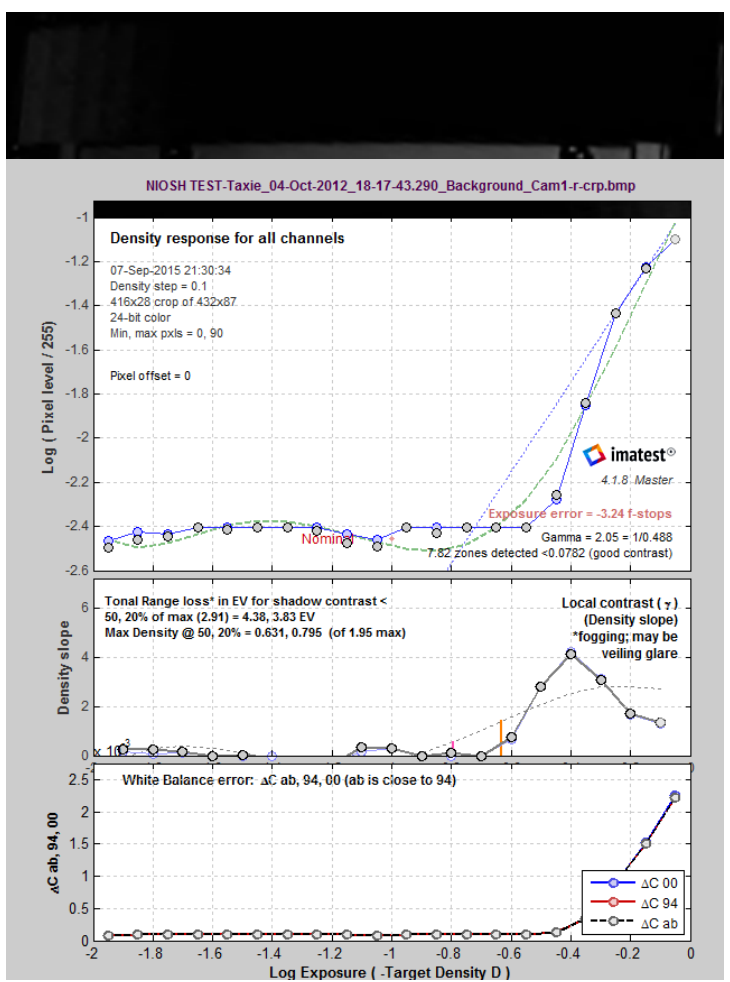

(c)

Figure 9. The camera shadow dynamic range test charts measured in recognizable gray steps: (a) 18.5 (most recognizable gray steps), (b) 16.6 (close to the threshold), and (c) 7.8 (unacceptable). 


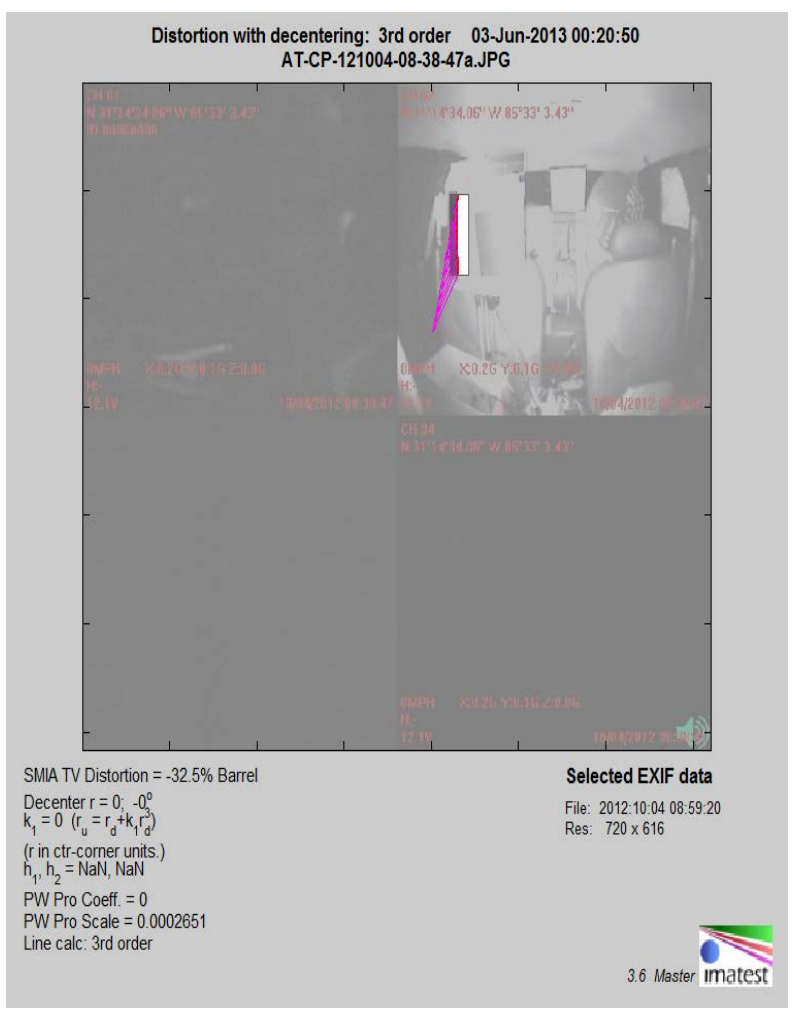

(a)

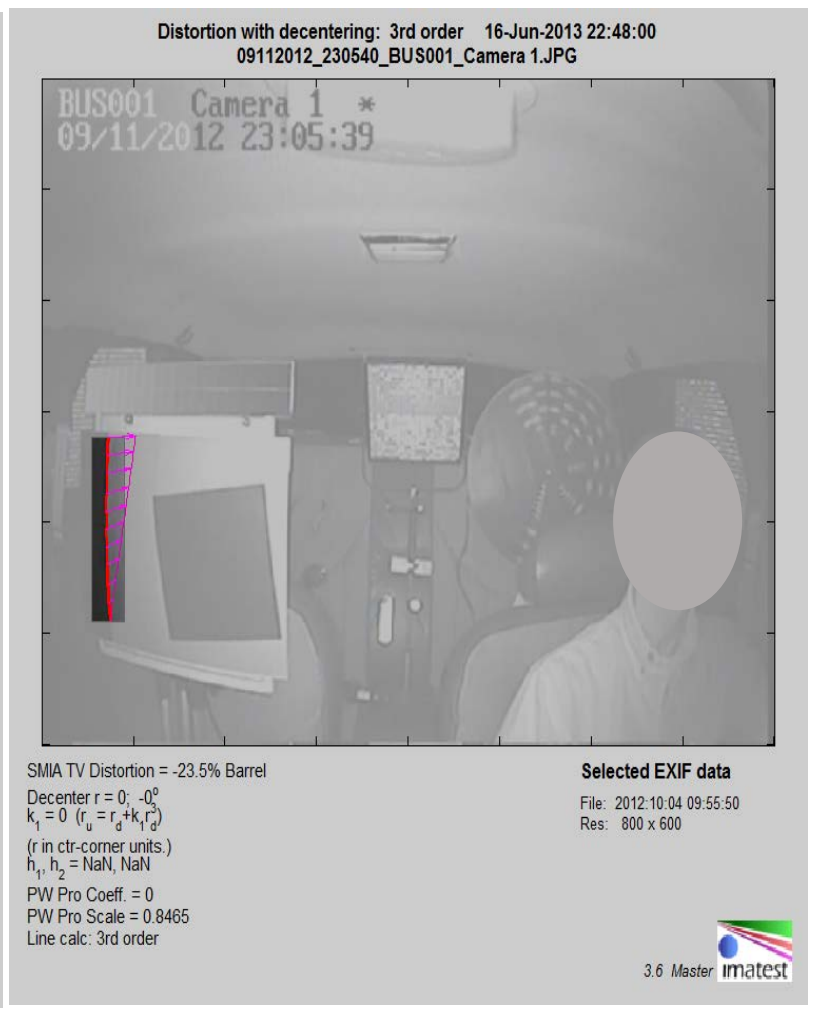

(b)

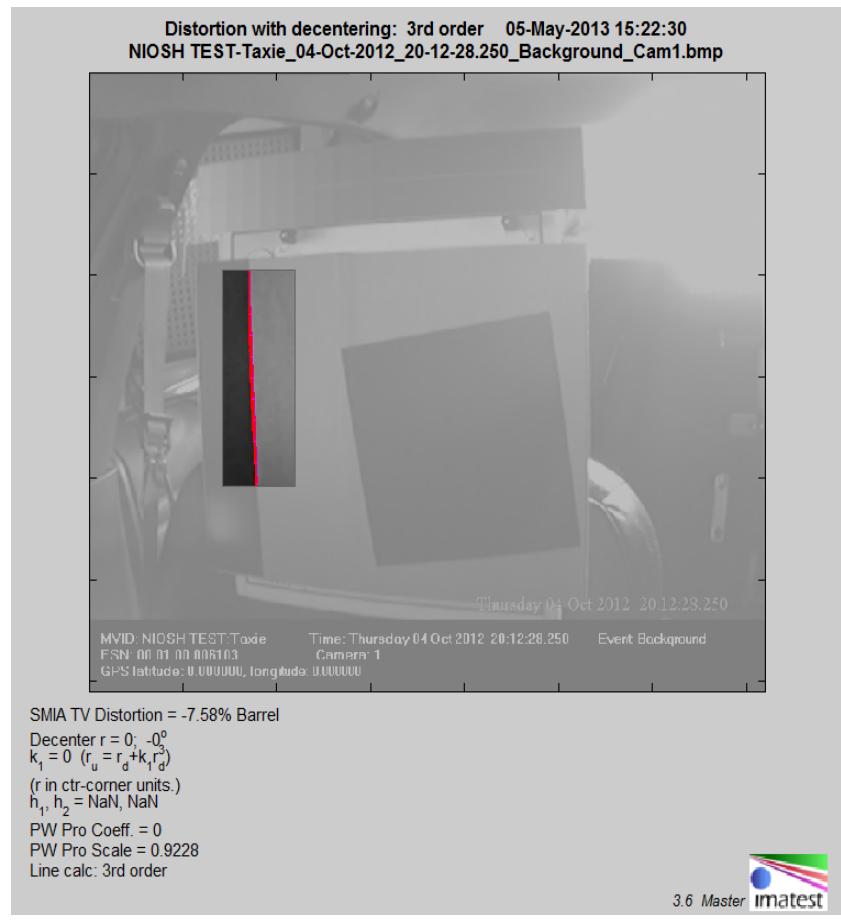

(c)

Figure 10. To compare different lens distortions of post-test images, three distorted test chart images, captured by three cameras with different lens distortions, and measured by "Distortion" module, are shown. The SMIA TV Distortion percentage on each chart is the lens distortion percentage of each test chart image. The minus sign before the number means barrel distortion. Three lens distortions are: (a) 32.5\% (worse than the lens distortion threshold, unacceptable); (b) 23.5\% (close to the lens distortion threshold) and (c) 7.5\% (least distorted, below the lens distortion threshold). 


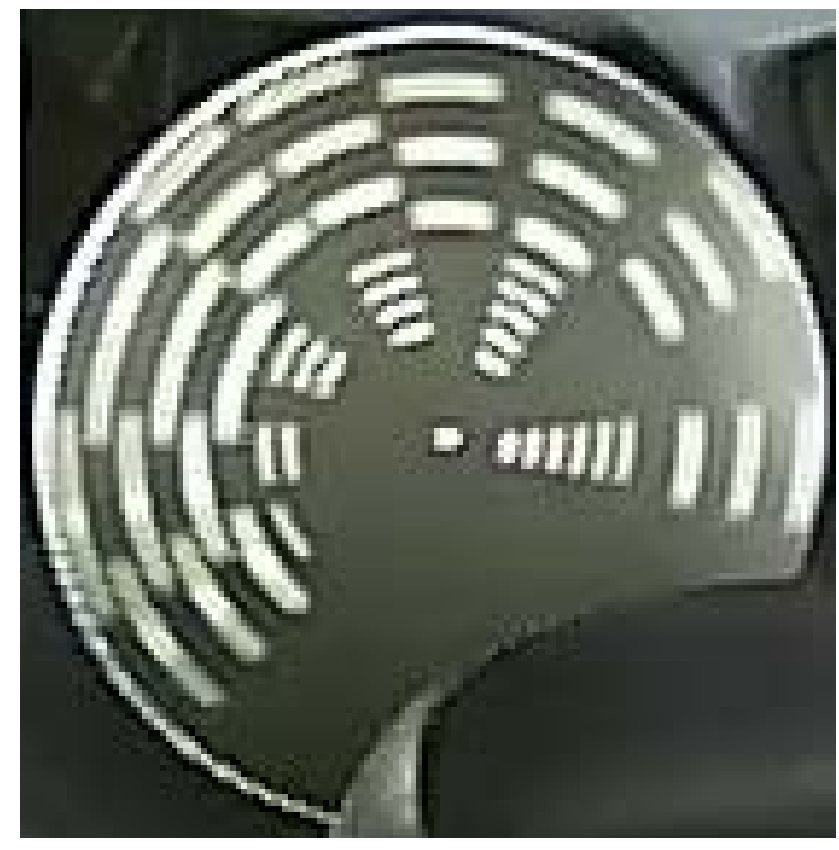

(a)



(b)



(c)

Figure 11. The images of the rotating shutter speed test charts are shown with three shutter speeds: (a) 40 ms slowest shutter, unacceptable); (b) $25 \mathrm{~ms}$ (close to mean shutter speed) and (c) $<16.7 \mathrm{~ms}$ (fastest shutter speed, much better than any shutter speed threshold). Signal Block is not shown in the charts.

memory card is submerged in tap-water. The waterproof survivability of six flash memory cards, three in Compact Flash form factor and three in Secure Digital (SD) form factor, were tested by submerging the cards in a water pipe. Before the waterproof test, two gigabytes of video clips were written on each of six memory cards by a PC. During the waterproof test, the memory cards were 
placed on the bottom of a PVC water pipe with the inner diameter of $100 \mathrm{~mm}$. The pipe was filled with five meters of tap-water. The flash memory cards were submerged in the water for 72 hours, as shown in Figure 12. Then, the memory cards were air dried at room temperature for 48 hours. Each of the dried memory cards was inserted into a PC, and the video clips stored on the cards were played by a PC to examine the integrity of the cards.

\subsection{Recording Media Fire Resistance Test Procedures}

To protect the recorded video data during a taxicab fire, the data storage media should be fire resistant. At the time this study was performed, there was no specific standard to regulate the fire resistance of taxicab recording media. Currently, there is no U.S. standard for taxicab fire resistance requirement. The "ASTM E119-15: Standard Test Methods for Fire Tests of Building Construction and Materials" [21] and "UL 72. Standard for Tests for Fire Resistance of Record Protection Equipment" [22] were used to define taxicab fire resistance requirement specifications. The purpose of this requirement was to ensure that the recording media of taxicab security cameras can be deemed as being able to provide "Resistance to Vehicle Fire". This specification was based on the lowest temperature tests defined in ASTM E119-15 and UL 72. The recording media may be considered as fire resistant to $538^{\circ} \mathrm{C}\left(1000^{\circ} \mathrm{F}\right)$ as per ASTM E119-15 methodology or equivalent certification [21].
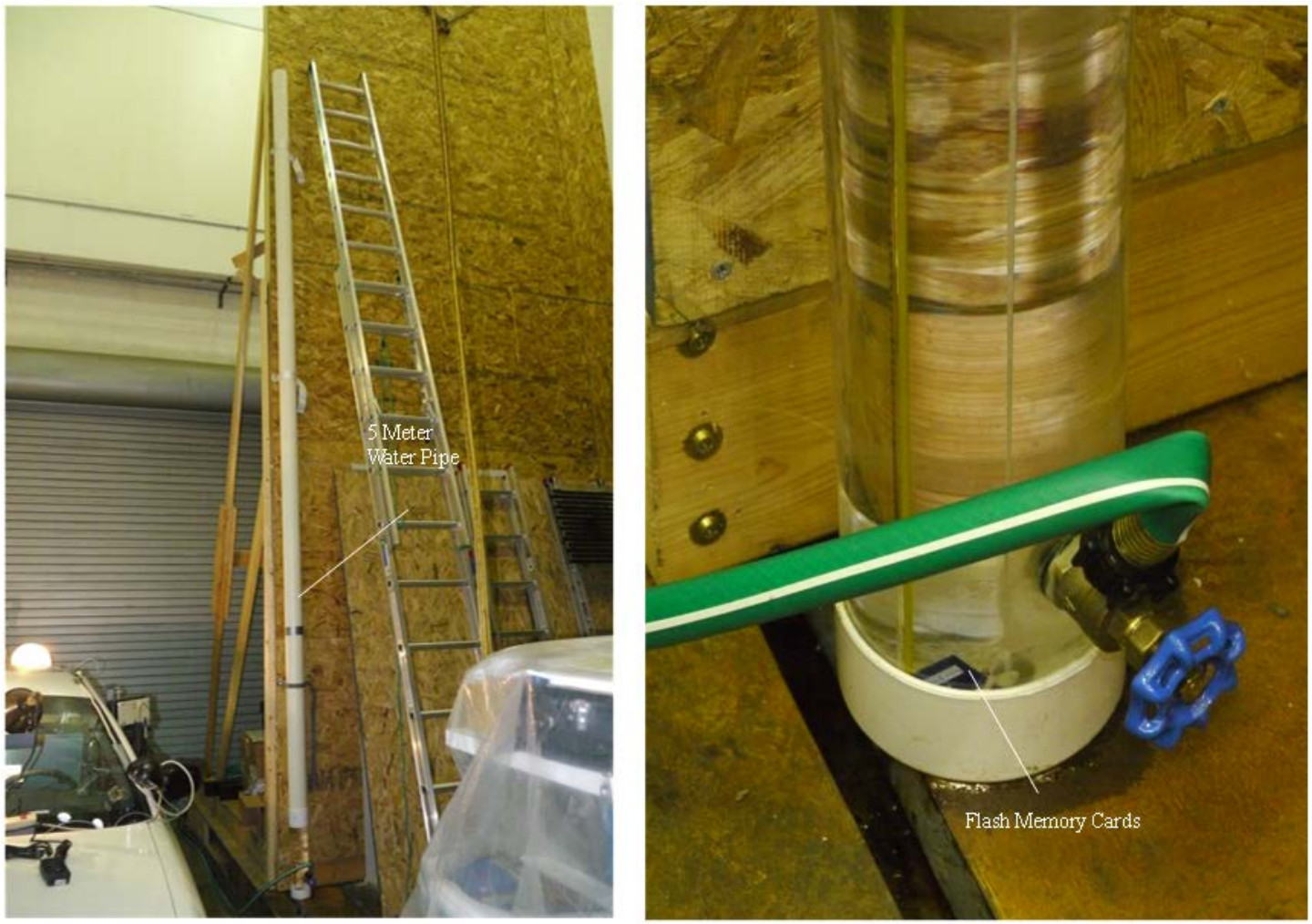

Figure 12. The experimental setup for flash memory card waterproof tests. The memory cards were submerged in the tap-water pipe at the depth of five meters for 72 hours. 
The Basic Fire Test comprised the following steps:

1) A furnace is heated to $538^{\circ} \mathrm{C}\left(1000^{\circ} \mathrm{F}\right)$.

2) The memory card in a fire resistant chamber is placed in the furnace.

3) After five minutes at $538^{\circ} \mathrm{C}\left(1000^{\circ} \mathrm{F}\right)$ the furnace is switched off.

4) The chamber is immediately removed from the furnace.

Once the chamber containing the memory card is removed from the furnace and allowed to cool to room temperature, the information on the memory card prior to it being placed in the furnace must be recovered.

Since there were no commercially available fire resistant chambers for taxicab security cameras, several fire resistant chambers were constructed for fire resistance tests conducted in this study. Based on the ASTM E119-15 temperature profiles in the fire resistance test, two materials were selected to construct the fire resistant chamber for ease of purchase, convenience, temperature rating, and performance. The materials, which were evaluated in the fire resistance tests, were thermal insulation material (TIM) No. 1 and thermal insulation material (TIM) No. 2. The properties are:

$\begin{array}{lcl} & \text { TIM No. } 1 & \text { TIM No. } 2 \\ \text { Max Temperature: } & 1260^{\circ} \mathrm{C}\left(2300^{\circ} \mathrm{F}\right) & \text { Not Given } \\ \text { Suggested Temp: } & 1176^{\circ} \mathrm{C}\left(2150^{\circ} \mathrm{F}\right) & 1000^{\circ} \mathrm{C}\left(1832^{\circ} \mathrm{F}\right) \\ \text { Thermal Conductivity }\left(300^{\circ} \mathrm{C}\right): & 0.079 & 0.029 \\ \text { Thermal Conductivity }\left(500^{\circ} \mathrm{C}\right): & 0.1045 & 0.035 \\ \text { Thermal Conductivity }\left(800^{\circ} \mathrm{C}\right) & 0.175 & 0.065 \\ \text { Strength }(\mathrm{MPa}): & 0.1915 & 0.1-0.22\end{array}$

A simplified analysis was performed using ANSYS Workbench 12.01 software (ANSYS, Inc., Canonsburg, PA) to estimate chamber thicknesses that might be used in the fire resistance test. The thickness of the fire resistance chamber was $25.4 \mathrm{~mm}$ (1.0"). In the tests, an SD flash memory card or flash card reader was placed in the chamber. Omega (Stamford, CT) XC-24-K-18 high temperature Nextel insulated thermocouples were inserted in the chamber and placed in the oven to measure chamber and oven temperature. A Model BF51732C Lindberg/Blue Thermo Scientific Furnace (Thermo Fisher Scientific, Inc., Waltham, MA) was used to generate the simulated fire temperature of $538^{\circ} \mathrm{C}\left(1000^{\circ} \mathrm{F}\right)$ for five minutes. The experimental setup for the fire resistance testing is shown in Figure 13.

\section{Results}

\subsection{Results of Post-Test Data Analyses}

The results of post-test data analyses are listed in Tables 2-7. For comparison, the metric thresholds in Table 1 were also listed in Tables 2-6. The measured data in five quality metrics (camera resolution, highlight dynamic range, shadow dynamic range, lens distortion, and shutter speed) with eight cameras were compared with the metric thresholds in Tables 2-6, respectively. The metric data which were worse than the thresholds are referred as "bad" data; and the metric data which were better than or equal to the thresholds are referred as "good" data. 


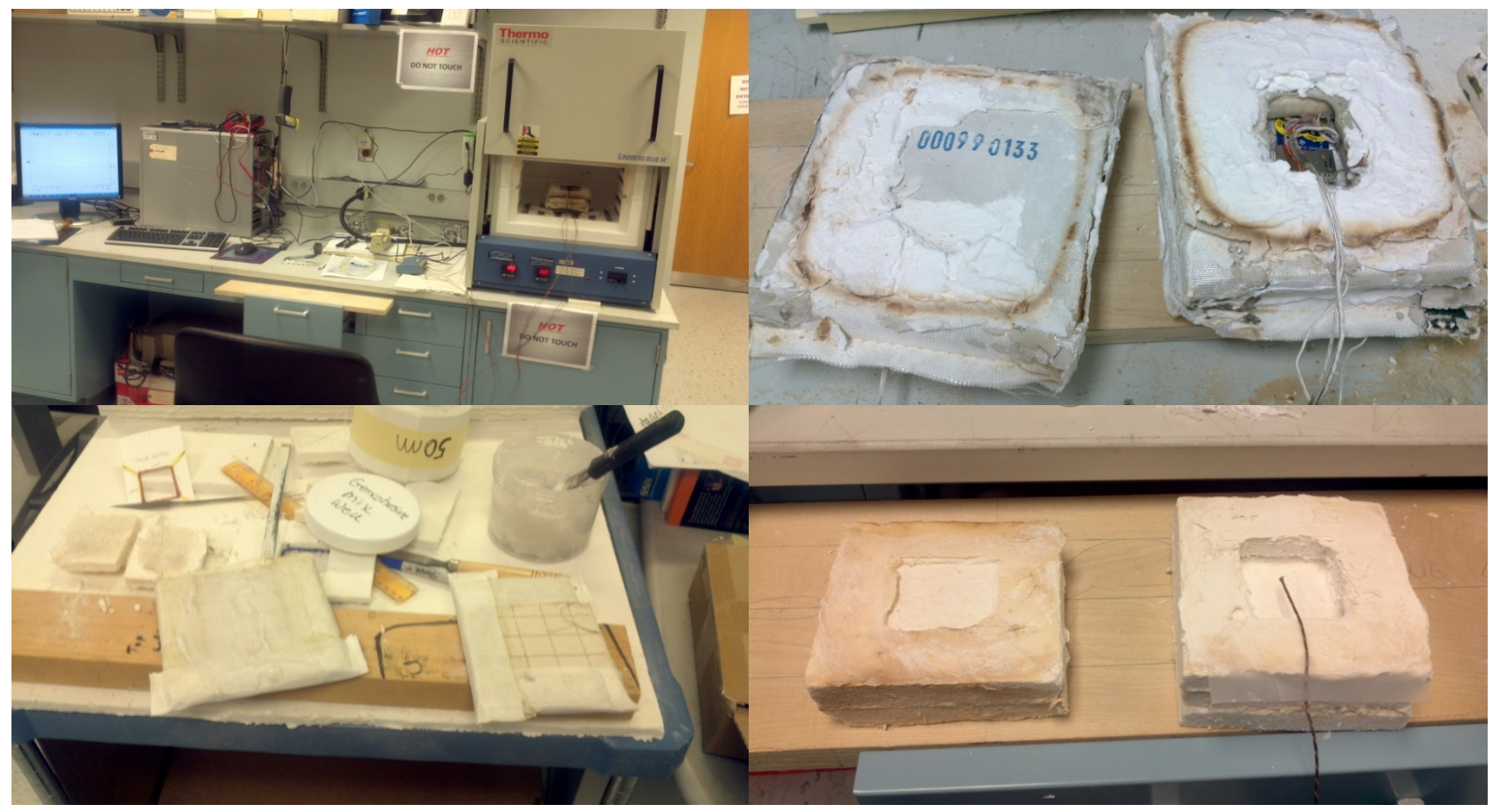

Figure 13. (Clockwise from top-left) (a) The overall experimental setup with data acquisition, thermocouples, and Thermo Scientific Furnace with proportional-integral-derivative control; (b) Piece of TIM No. 2 insulation which formed the cover of the insulation-box; (c) A TIM No. 1 multi-layer box to hold card; (d) Work-table for cutting and adhesive operations using insulation-refractory type paste to fix pieces together.

Table 2. Sample camera test results: resolution. Unit: line-widths per head height (LPHH).

\begin{tabular}{|c|c|c|c|c|c|c|c|c|c|c|c|}
\hline \multirow[b]{2}{*}{ Seat } & \multirow[b]{2}{*}{ Light } & \multirow{2}{*}{$\begin{array}{l}\text { Threshold } \\
\text { for Color } \\
\text { Images }\end{array}$} & \multirow{2}{*}{$\begin{array}{l}\text { Threshold for } \\
\text { B \& W Images }\end{array}$} & \multicolumn{8}{|c|}{ Test Results } \\
\hline & & & & $\begin{array}{c}\text { C1 } \\
\text { (Color) }\end{array}$ & $\begin{array}{c}\text { C2 } \\
\text { (Color) }\end{array}$ & $\begin{array}{c}\text { C3 } \\
(B \& W)\end{array}$ & $\begin{array}{c}\text { C4 } \\
(B \& W)\end{array}$ & $\begin{array}{c}{ }^{*} \mathrm{C} 5 \\
\text { (Color) }\end{array}$ & $\begin{array}{c}{ }^{*} \mathrm{C} 6 \\
\text { (Color) }\end{array}$ & $\begin{array}{c}\text { C7 } \\
\text { (Color) }\end{array}$ & $\begin{array}{c}\text { C8 } \\
\text { (Color) }\end{array}$ \\
\hline \multirow{4}{*}{ Rear-Middle } & L1: Daylight & $\geq 61.8$ & $\geq 59.2$ & 100.2 & 83.3 & 55.9 & 47.3 & 29.6 & 34.9 & 63.0 & 44.0 \\
\hline & L2: Dark & - & $\geq 75.0$ & 59.6 & ${ }^{\star A} \mathrm{~A}$ & 59.5 & 38.1 & 32.4 & ${ }^{*} \mathrm{~B}$ & 56.8 & 41.3 \\
\hline & L3: Dark-BL & - & $\geq 40.3$ & 61.2 & ${ }^{\star A} \mathrm{~A}$ & 57.7 & 38.4 & 30.2 & ${ }^{*} \mathrm{~B}$ & 84.5 & 40.2 \\
\hline & L4: Sunset-RW & $\geq 44.9$ & $\geq 47.3$ & 84.4 & ${ }^{*} \mathrm{~A}$ & 52.7 & 49.9 & 32.0 & ${ }^{*} \mathrm{~B}$ & 59.6 & 43.8 \\
\hline \multirow{4}{*}{ Rear-Right } & L1: Daylight & $\geq 47.7$ & $\geq 47.1$ & 101.6 & 80.1 & 60.0 & 49.6 & 33.5 & ${ }^{*} \mathrm{~B}$ & 80.5 & 44.1 \\
\hline & L2: Dark & - & $\geq 46.8$ & 57.8 & ${ }^{\star} \mathrm{A}$ & 62.6 & 44.9 & 21.3 & 15.5 & 54.5 & 34.6 \\
\hline & L3: Dark-BL & - & $\geq 42.2$ & 58.2 & ${ }^{\star} \mathrm{A}$ & ${ }^{\star} \mathrm{C}$ & ${ }^{\star} \mathrm{C}$ & ${ }^{*} \mathrm{C}$ & ${ }^{\star} \mathrm{C}$ & 6.4 & ${ }^{\star} \mathrm{C}$ \\
\hline & L4: Sunset-RW & $\geq 45.7$ & $\geq 74.0$ & 87.8 & ${ }^{\star A}$ & 51.1 & 43.3 & ${ }^{\star} \mathrm{B}$ & ${ }^{*} \mathrm{~B}$ & 67.9 & ${ }^{\star} \mathrm{E}$ \\
\hline \multirow{4}{*}{ Front-Right } & L1: Daylight & $\geq 47.8$ & $\geq 52.4$ & 220.3 & ${ }^{\star} \mathrm{A}$ & 123.6 & 97.1 & 63.4 & ${ }^{*} \mathrm{~B}$ & 187.5 & 86.5 \\
\hline & L2: Dark & - & $\geq 51.8$ & 159.6 & ${ }^{\star A}$ & 142.1 & 81.6 & 62.2 & 70.7 & 82.8 & 82.6 \\
\hline & L3: Dark-BL & - & $\geq 62.0$ & 134.1 & ${ }^{\star} \mathrm{A}$ & 51.4 & 51.4 & 34.9 & 49.9 & 160.0 & 84.4 \\
\hline & L4: Sunset-RW & $\geq 48.6$ & $\geq 39.5$ & 171.5 & ${ }^{*} \mathrm{~A}$ & 152.1 & 76.5 & 51.0 & 61.0 & 154.3 & 92.2 \\
\hline
\end{tabular}

${ }^{\star} \mathrm{A}$ : Only two sets of data were measured before Camera C2 was withdrawn during sample camera tests. ${ }^{\star} \mathrm{B}$ : Excessively overexposed. Data could not be measured. ${ }^{\star} \mathrm{C}$ : IR-LED radiation source was not activated. Data could not be measured in dark conditions. ${ }^{\star} \mathrm{C} 5$, ${ }^{\star} \mathrm{C} 6$ : The images captured by C5 and C6 were shown in only one quadrant of the image viewer screen. 
Table 3. Sample camera test results: highlight dynamic range. Unit: merged gray steps.

\begin{tabular}{|c|c|c|c|c|c|c|c|c|c|c|c|}
\hline \multirow[b]{2}{*}{ Seat } & \multirow[b]{2}{*}{ Light } & \multirow{2}{*}{$\begin{array}{l}\text { Threshold } \\
\text { for Color } \\
\text { Images }\end{array}$} & \multirow{2}{*}{$\begin{array}{l}\text { Threshold for } \\
\text { B \& W Images }\end{array}$} & \multicolumn{8}{|c|}{ Test Results } \\
\hline & & & & $\begin{array}{c}\text { C1 } \\
\text { (Color) }\end{array}$ & $\begin{array}{c}\mathrm{C} 2 \\
\text { (Color) }\end{array}$ & $\begin{array}{c}\text { C3 } \\
(B \& W)\end{array}$ & $\begin{array}{c}\text { C4 } \\
(B \& W)\end{array}$ & $\begin{array}{c}{ }^{*} \mathrm{C5} \\
\text { (Color) }\end{array}$ & $\begin{array}{c}{ }^{*} \mathrm{C6} \\
\text { (Color) }\end{array}$ & $\begin{array}{c}\text { C7 } \\
\text { (Color) }\end{array}$ & $\begin{array}{c}\text { C8 } \\
\text { (Color) }\end{array}$ \\
\hline \multirow{2}{*}{ Rear-Middle } & L1: Daylight & $\leq 5.7$ & $\leq 4.6$ & 3.4 & 2.2 & 1.2 & 4.1 & ${ }^{*} \mathrm{D}$ & $>>6$ & 3.9 & 5.3 \\
\hline & L4: Sunset-RW & $\leq 5.5$ & $\leq 5.7$ & 2.8 & ${ }^{*} \mathrm{~A}$ & 1.6 & 6.6 & ${ }^{*} \mathrm{D}$ & $>>6$ & 2.4 & 2.9 \\
\hline \multirow{2}{*}{ Rear-Right } & L1: Daylight & $\leq 6.3$ & $\leq 5.3$ & 4.3 & 2.4 & 0.0 & 4.6 & ${ }^{*} \mathrm{D}$ & $>>6$ & 4.4 & 5.8 \\
\hline & L4: Sunset-RW & $\leq 6.2$ & $\leq 4.2$ & 1.3 & ${ }^{*} \mathrm{~A}$ & 2.4 & 0.0 & ${ }^{*} \mathrm{C}$ & $>>6$ & 0.0 & 0.0 \\
\hline \multirow{2}{*}{ Front-Right } & L1: Daylight & $\leq 5.1$ & $\leq 4.3$ & 7.7 & ${ }^{*} \mathrm{~A}$ & 7.2 & $>>6$ & 8.2 & $>>6$ & 5.6 & 7.4 \\
\hline & L4: Sunset-RW & $\leq 4.8$ & $\leq 3.3$ & 1.4 & ${ }^{*} \mathrm{~A}$ & 2.0 & ${ }^{*} \mathrm{~B}$ & 0.0 & ${ }^{\star} \mathrm{E}$ & 0.0 & 1.4 \\
\hline
\end{tabular}

${ }^{*}$ A: Only two sets of data were measured before Camera $\mathrm{C} 2$ was withdrawn during sample camera tests. ${ }^{*} \mathrm{~B}$ : The lens view angle was too narrow to cover whole gray scale. Reliable measurement was not possible. ${ }^{\star} \mathrm{C}$ : Excessively overexposed. Data could not be measured. ${ }^{\star} \mathrm{D}$ : Very low resolution, pseudo color, and noisy. Data could not be measured. ${ }^{\star}$ E: Low resolution and noisy. Data measurement was not reliable. ${ }^{\star} \mathrm{C} 5$, ${ }^{\star} \mathrm{C} 6$ : The images captured by C5 and C6 were shown in only one quadrant of the image viewer screen.

Table 4. Sample camera test results: shadow dynamic range. Unit: recognizable gray steps.

\begin{tabular}{|c|c|c|c|c|c|c|c|c|c|c|c|}
\hline \multirow[b]{2}{*}{ Seat } & \multirow[b]{2}{*}{ Light } & \multirow{2}{*}{$\begin{array}{l}\text { Threshold } \\
\text { for Color } \\
\text { Images }\end{array}$} & \multirow{2}{*}{$\begin{array}{l}\text { Threshold } \\
\text { for B \& W } \\
\text { Images }\end{array}$} & \multicolumn{8}{|c|}{ Test Results } \\
\hline & & & & $\begin{array}{c}\mathrm{C} 1 \\
\text { (Color) }\end{array}$ & $\begin{array}{c}\mathrm{C} 2 \\
\text { (Color) }\end{array}$ & $\begin{array}{c}\text { C3 } \\
(B \& W)\end{array}$ & $\begin{array}{c}\mathrm{C} 4 \\
(\mathrm{~B} \& \mathrm{~W})\end{array}$ & $\begin{array}{l}{ }^{*} \mathrm{C} 5 \\
(\text { Color })\end{array}$ & $\begin{array}{l}{ }^{*} \mathrm{C} 6 \\
\text { (Color) }\end{array}$ & $\begin{array}{c}\text { C7 } \\
\text { (Color) }\end{array}$ & $\begin{array}{c}\text { C8 } \\
\text { (Color) }\end{array}$ \\
\hline \multirow{2}{*}{ Rear-Middle } & L1: Daylight & $\geq 13.8$ & $\geq 16.8$ & ${ }^{\star} \mathrm{E}$ & ${ }^{\star} \mathrm{E}$ & ${ }^{\star} \mathrm{E}$ & ${ }^{*} \mathrm{E}$ & ${ }^{\star} \mathrm{E}$ & ${ }^{\star} \mathrm{E}$ & ${ }^{\star} \mathrm{E}$ & ${ }^{\star} \mathrm{E}$ \\
\hline & L2: Dark & - & $\geq 13.2$ & 17.8 & ${ }^{*} \mathrm{~A}$ & 18.7 & 18.7 & ${ }^{*} \mathrm{D}$ & ${ }^{*} \mathrm{C}$ & 16.3 & 17.2 \\
\hline \multirow{2}{*}{ Rear-Right } & L1: Daylight & $\geq 12.6$ & $\geq 18$ & ${ }^{\star} \mathrm{E}$ & *E & 18.3 & ${ }^{\star} \mathrm{E}$ & ${ }^{\star} \mathrm{E}$ & ${ }^{\star} \mathrm{E}$ & ${ }^{\star} \mathrm{E}$ & ${ }^{\star} \mathrm{E}$ \\
\hline & L2: Dark & - & $\geq 17.3$ & 14.6 & ${ }^{*} \mathrm{~A}$ & 16.4 & 15.8 & ${ }^{\star} \mathrm{D}$ & ${ }^{\star} \mathrm{C}$ & 15.8 & 16.5 \\
\hline \multirow{2}{*}{ Front-Right } & L1: Daylight & $\geq 12.1$ & $\geq 15.0^{* *}$ & ${ }^{\star} \mathrm{E}$ & ${ }^{*} \mathrm{~A}$ & ${ }^{\star} \mathrm{E}$ & *E & ${ }^{\star} \mathrm{E}$ & ${ }^{\star} \mathrm{E}$ & ${ }^{\star} \mathrm{E}$ & ${ }^{\star} \mathrm{E}$ \\
\hline & L2: Dark & - & $\geq 16.3$ & 17.2 & ${ }^{*} \mathrm{~A}$ & 17.3 & ${ }^{*} \mathrm{~B}$ & 17.0 & ${ }^{\star} \mathrm{C}$ & 15.1 & 17.7 \\
\hline
\end{tabular}

${ }^{\star} \mathrm{A}$ : Only two sets of data were measured before Camera C2 was withdrawn during sample camera tests. ${ }^{\star} \mathrm{B}$ : The lens view angle was too narrow to cover whole gray scale. Reliable measurement was not possible ${ }^{\star} \mathrm{C}$ : Excessively overexposed. Data could not be measured. ${ }^{\star} \mathrm{D}$ : Very low resolution, pseudo color, and noisy. Data could not be measured. ${ }^{\star} \mathrm{E}$ : The data had merged (washed out) gray steps, therefore, the recognizable gray steps could not be measured. ${ }^{\star *}$ : Unable to measure the shadow dynamic range threshold by Imatest software due to vulnerable light conditions. The threshold value was substituted by the median of the shadow dynamic range threshold set (15.0 Recognizable Gray Steps). ${ }^{*}$ C5, ${ }^{*}$ C6: The images captured by C5 and C6 were shown in only one quadrant of the image viewer screen.

Table 5. Sample camera test results: lens distortion. Unit: \%.

\begin{tabular}{|c|c|c|c|c|c|c|c|c|c|c|c|}
\hline \multirow[b]{2}{*}{ Seat } & \multirow[b]{2}{*}{ Light } & \multirow{2}{*}{$\begin{array}{l}\text { Threshold for } \\
\text { Color Images }\end{array}$} & \multirow{2}{*}{$\begin{array}{c}\text { Threshold for } \\
\text { B \& W } \\
\text { Images }\end{array}$} & \multicolumn{8}{|c|}{ Test Results } \\
\hline & & & & $\begin{array}{c}\text { C1 } \\
\text { (Color) }\end{array}$ & $\begin{array}{c}\text { C2 } \\
\text { (Color) }\end{array}$ & $\begin{array}{c}\text { C3 } \\
(B \& W)\end{array}$ & $\begin{array}{c}\text { C4 } \\
(B \& W)\end{array}$ & $\begin{array}{c}{ }^{*} \mathrm{C5} \\
\text { (Color) }\end{array}$ & $\begin{array}{c}{ }^{*} \mathrm{C6} \\
\text { (Color) }\end{array}$ & $\begin{array}{c}\text { C7 } \\
\text { (Color) }\end{array}$ & $\begin{array}{c}\text { C8 } \\
\text { (Color) }\end{array}$ \\
\hline \multirow{4}{*}{ Front-Right } & L1: Daylight & $\leq 24.4$ & $\leq 24.4$ & 17.0 & ${ }^{*} \mathrm{~A}$ & 8.8 & 12.4 & 20.5 & ${ }^{*} \mathrm{D}$ & 19.6 & $* * 30.5$ \\
\hline & L2: Dark & - & $\leq 24.4$ & 15.0 & ${ }^{*} \mathrm{~A}$ & 8.4 & 16.7 & 15.3 & 32.3 & ${ }^{*} \mathrm{C}$ & 23.4 \\
\hline & L3: Dark-BL & - & $\leq 24.4$ & 17.5 & ${ }^{*} \mathrm{~A}$ & ${ }^{*} \mathrm{~B}$ & ${ }^{*} \mathrm{~B}$ & 20.8 & 33.5 & 23.2 & 23.4 \\
\hline & L4: Sunset-RW & $\leq 24.4$ & $\leq 24.4$ & 17.0 & ${ }^{*} \mathrm{~A}$ & 7.5 & 18.2 & 19.6 & 33.3 & 20.2 & $* * 31.7$ \\
\hline
\end{tabular}

${ }^{\star}$ A: Only two sets of data were measured before Camera C2 was withdrawn during sample camera tests. ${ }^{\star}$ B: IR-LED light source was not activated. Data could not be measured in dark conditions. ${ }^{\star} \mathrm{C}$ : Due to the narrow IR-LED radiation angle, the light condition was too dark, and the lens distortion could not be measured. ${ }^{\star} \mathrm{D}$ : The test chart image was washed out due to overexposure. ${ }^{\star *}$ : The distortion value is higher than those measured in L2 and $\mathrm{L} 3$ light conditions. This phenomenon was caused by the camera's over-sharpening effect in L1 and L4 conditions, which was not related to lens distortion. ${ }^{\star} \mathrm{C} 5$, ${ }^{\star} \mathrm{C} 6$ : The images captured by C5 and C6 were shown in only one quadrant of the image viewer screen. 
Table 6. Sample camera test results: shutter speed. Unit: millisecond.

\begin{tabular}{|c|c|c|c|c|c|c|c|c|c|c|c|}
\hline \multirow[b]{2}{*}{ Seat } & \multirow[b]{2}{*}{ Light } & \multirow{2}{*}{$\begin{array}{l}\text { Threshold } \\
\text { for Color } \\
\text { Images }\end{array}$} & \multirow{2}{*}{$\begin{array}{l}\text { Threshold } \\
\text { for B \& W } \\
\text { Images }\end{array}$} & \multicolumn{8}{|c|}{ Test Results } \\
\hline & & & & $\begin{array}{c}\mathrm{C} 1 \\
\text { (Color) }\end{array}$ & $\begin{array}{c}\text { C2 } \\
\text { (Color) }\end{array}$ & $\begin{array}{c}\text { C3 } \\
(B \& W)\end{array}$ & $\begin{array}{c}\mathrm{C} 4 \\
(\mathrm{~B} \& \mathrm{~W})\end{array}$ & $\begin{array}{c}{ }^{*} \mathrm{C} 5 \\
\text { (Color) }\end{array}$ & $\begin{array}{c}{ }^{*} \mathrm{C} 6 \\
\text { (Color) }\end{array}$ & $\begin{array}{c}\text { C7 } \\
\text { (Color) }\end{array}$ & $\begin{array}{c}\text { C8 } \\
\text { (Color) }\end{array}$ \\
\hline \multirow{4}{*}{ Rear-Middle } & L1: Daylight & $\leq 33.3$ & $\leq 36.7$ & 33.3 & 20.0 & 25.0 & 20.0 & 20.0 & 25.0 & 40.0 & 20.0 \\
\hline & L2: Dark & - & $\leq 33.3$ & 33.3 & ${ }^{*} \mathrm{~A}$ & 25.0 & 21.7 & 20.0 & 20.0 & 33.3 & 25.0 \\
\hline & L3: Dark-BL & - & $\leq 33.3$ & 33.3 & ${ }^{\star} \mathrm{A}$ & 25.0 & 23.3 & 20.0 & 20.0 & 33.3 & 25.0 \\
\hline & L4: Sunset-RW & $\leq 33.3$ & $\leq 33.3$ & 33.3 & ${ }^{*} \mathrm{~A}$ & 25.0 & 20.0 & 20.0 & 20.0 & 33.3 & 20.0 \\
\hline
\end{tabular}

${ }^{*} \mathrm{~A}$ : Only two sets of data were measured before Camera $\mathrm{C} 2$ was withdrawn during sample camera tests. ${ }^{*} \mathrm{C} 5$, ${ }^{*} \mathrm{C} 6$ : The images captured by $\mathrm{C} 5$ and $\mathrm{C} 6$ were shown in only one quadrant of the image viewer screen.

The infrared radiation sources of seven cameras (except C2, which was not tested in L3 condition) tested were not activated in L3 (dark with backlight) light conditions in the rear-right seat position, and five cameras $(\mathrm{C} 4 \sim \mathrm{C} 8)$ did not activate their infrared radiation sources in $\mathrm{L} 3$ and in the front-right seat position. A summary of infrared radiation source activations in L3 condition is shown in Table 7.

Table 7. Sample camera test results: infrared radiation source activation.

\begin{tabular}{|c|c|c|c|c|c|c|c|c|c|}
\hline \multirow[b]{2}{*}{ Seat } & \multirow[b]{2}{*}{ Light } & \multicolumn{8}{|c|}{ Test Results } \\
\hline & & $\begin{array}{c}\mathrm{C} 1 \\
\text { (Color) }\end{array}$ & $\begin{array}{c}\text { C2 } \\
\text { (Color) }\end{array}$ & $\begin{array}{c}\text { C3 } \\
(\mathrm{B} \& \mathrm{~W})\end{array}$ & $\begin{array}{c}C 4 \\
(B \& W)\end{array}$ & $\begin{array}{c}{ }^{*} \mathrm{C} 5 \\
\text { (Color) }\end{array}$ & $\begin{array}{c}{ }^{*} \mathrm{C} 6 \\
\text { (Color) }\end{array}$ & $\begin{array}{c}\text { C7 } \\
\text { (Color) }\end{array}$ & $\begin{array}{c}\text { C8 } \\
\text { (Color) }\end{array}$ \\
\hline Rear-Middle & & Yes & ${ }^{*} \mathrm{~A}$ & Yes & Yes & Yes & Yes & Yes & Yes \\
\hline Rear-Right & L3: Dark-BL & No & ${ }^{*} \mathrm{~A}$ & No & No & No & No & No & No \\
\hline Front-Right & & Yes & ${ }^{\star} \mathrm{A}$ & Yes & No & No & No & No & No \\
\hline
\end{tabular}

${ }^{*} \mathrm{~A}$ : Only two sets of data were measured before Camera C2 was withdrawn during sample camera tests. ${ }^{*} \mathrm{C} 5$, ${ }^{*} \mathrm{C} 6$ : The images captured by $\mathrm{C} 5$ and $\mathrm{C} 6$ were shown in only one quadrant of the image viewer screen.

A summary of the camera performance for each metric and the ranking are listed in Table 8. The effectiveness of a camera was determined by the number of "good" metric data. A camera would rank higher in a metric with more "good" data, and vice versa. As two cameras had the same number of "good" data, the one with better median performance value in that metric would have a higher rank. The median performance value is the median of all of the performance data of a camera in one metric and in all light and seat conditions. A summary of the metric performances with each camera and the total performance ranking are listed in Table 9. The metric performance of the cameras with the maximum, median and minimum values are shown in Table 10.

\subsection{Camera Ranks}

Camera $\mathrm{C} 1$ with an FHD image sensor had the highest photographic resolution rank. Camera C3 with two separate lenses, one focused on the left-hand side of the cab and another focused on the right-hand side, had the highest rank in both 
Table 8. Camera performance ranks of quality metrics.

\begin{tabular}{|c|c|c|c|c|c|}
\hline Metric & Camera & $\begin{array}{l}\text { Better than } \\
\text { or Equal to } \\
\text { Threshold }\end{array}$ & $\begin{array}{l}\text { Worse than } \\
\text { Threshold }\end{array}$ & $\begin{array}{l}\text { Median } \\
\text { Perform. }\end{array}$ & Rank \\
\hline \multirow{8}{*}{ Resolution } & 1 & 11 & 1 & 94.0 & 1 \\
\hline & 2 & 2 & 0 & 81.7 & ${ }^{*}$ Incomplete Data \\
\hline & 3 & 7 & 5 & 58.6 & 3 \\
\hline & 4 & 5 & 7 & 48.5 & 4 \\
\hline & 5 & 3 & 9 & 31.1 & 6 \\
\hline & 6 & 2 & 10 & 6.4 & 7 \\
\hline & 7 & 10 & 2 & 74.2 & 2 \\
\hline & 8 & 4 & 8 & 43.9 & 5 \\
\hline \multirow{8}{*}{$\begin{array}{c}\text { Dynam. } \\
\text { HL }\end{array}$} & 1 & 5 & 1 & 3.1 & 2 \\
\hline & 2 & 2 & 0 & 2.3 & ${ }^{*}$ Incomplete Data \\
\hline & 3 & 5 & 1 & 1.8 & 1 \\
\hline & 4 & 3 & 3 & 5.6 & 5 \\
\hline & 5 & 1 & 5 & 8.2 & 6 \\
\hline & 6 & 0 & 6 & 8.2 & 7 \\
\hline & 7 & 5 & 1 & 3.2 & 3 \\
\hline & 8 & 5 & 1 & 4.1 & 4 \\
\hline \multirow{8}{*}{$\begin{array}{l}\text { Dynam. } \\
\text { SD }\end{array}$} & 1 & 2 & 4 & 17.2 & 2 \\
\hline & 2 & - & 2 & - & ${ }^{*}$ Incomplete Data \\
\hline & 3 & 3 & 3 & 17.8 & 1 \\
\hline & 4 & 1 & 5 & 17.3 & 4 \\
\hline & 5 & 1 & 5 & 17.0 & 5 \\
\hline & 6 & 0 & 6 & - & 7 \\
\hline & 7 & 1 & 5 & 15.8 & 6 \\
\hline & 8 & 2 & 4 & 17.2 & 2 \\
\hline \multirow{8}{*}{$\begin{array}{l}\text { Lens Dis- } \\
\text { tortion }\end{array}$} & 1 & 4 & 0 & 17.0 & 1 \\
\hline & 2 & - & - & - & ${ }^{*}$ Incomplete Data \\
\hline & 3 & 3 & 1 & 8.4 & 3 \\
\hline & 4 & 3 & 1 & 16.7 & 4 \\
\hline & 5 & 4 & 0 & 20.0 & 2 \\
\hline & 6 & 0 & 4 & 33.3 & 7 \\
\hline & 7 & 3 & 1 & 20.2 & 5 \\
\hline & 8 & 2 & 2 & 27.0 & 6 \\
\hline \multirow{8}{*}{$\begin{array}{l}\text { Shutter } \\
\text { Speed }\end{array}$} & 1 & 4 & 0 & 33.3 & 6 \\
\hline & 2 & 1 & - & 20 & ${ }^{\star}$ Incomplete Data \\
\hline & 3 & 4 & 0 & 25.0 & 5 \\
\hline & 4 & 4 & 0 & 20.8 & 3 \\
\hline & 5 & 4 & 0 & 20.0 & 1 \\
\hline & 6 & 4 & 0 & 20.0 & 1 \\
\hline & 7 & 3 & 1 & 33.3 & 7 \\
\hline & 8 & 4 & 0 & 22.5 & 4 \\
\hline \multirow{8}{*}{ Total Data } & 1 & 26 & 6 & - & 1 \\
\hline & 2 & 5 & 2 & - & ${ }^{*}$ Incomplete Data \\
\hline & 3 & 22 & 10 & - & 2 \\
\hline & 4 & 16 & 16 & - & 5 \\
\hline & 5 & 13 & 19 & - & 6 \\
\hline & 6 & 6 & 26 & - & 7 \\
\hline & 7 & 22 & 10 & - & 2 \\
\hline & 8 & 17 & 15 & - & 4 \\
\hline
\end{tabular}


Table 9. Metric performance ranks for each camera.

\begin{tabular}{|c|c|c|c|c|c|c|}
\hline Camera & Metric & $\begin{array}{c}\text { Better than or } \\
\text { Equal to } \\
\text { Threshold }\end{array}$ & $\begin{array}{l}\text { Worse than } \\
\text { Threshold }\end{array}$ & $\begin{array}{l}\text { Median } \\
\text { Perform. }\end{array}$ & Rank & Total Rank \\
\hline \multirow{5}{*}{1} & Resolution & 11 & 1 & 94.0 & 1 & \multirow{5}{*}{1} \\
\hline & Dynam. HL & 5 & 1 & 3.1 & 2 & \\
\hline & Dynam. SD & 2 & 4 & 17.2 & 2 & \\
\hline & Distortion & 4 & 0 & 17.0 & 1 & \\
\hline & Shutter Speed & 4 & 0 & 33.3 & 6 & \\
\hline \multirow{5}{*}{2} & Resolution & 2 & 0 & 81.7 & ${ }^{\star}$ Incomplete Data & \multirow{5}{*}{${ }^{\star}$ Incomplete Data } \\
\hline & Dynam. HL & 2 & 0 & 2.3 & ${ }^{\star}$ Incomplete Data & \\
\hline & Dynam. SD & - & 2 & - & ${ }^{\star}$ Incomplete Data & \\
\hline & Distortion & - & - & - & ${ }^{\star}$ Incomplete Data & \\
\hline & Shutter Speed & 1 & - & 20 & ${ }^{\star}$ Incomplete Data & \\
\hline \multirow{5}{*}{3} & Resolution & 7 & 5 & 58.6 & 3 & \multirow{5}{*}{2} \\
\hline & Dynam. HL & 5 & 1 & 1.8 & 1 & \\
\hline & Dynam. SD & 3 & 3 & 17.8 & 1 & \\
\hline & Distortion & 3 & 1 & 8.4 & 3 & \\
\hline & Shutter Speed & 4 & 0 & 25.0 & 5 & \\
\hline \multirow{5}{*}{4} & Resolution & 5 & 7 & 48.5 & 4 & \multirow{5}{*}{5} \\
\hline & Dynam. HL & 3 & 3 & 5.6 & 5 & \\
\hline & Dynam. SD & 1 & 5 & 17.3 & 4 & \\
\hline & Distortion & 3 & 1 & 16.7 & 4 & \\
\hline & Shutter Speed & 4 & 0 & 20.8 & 3 & \\
\hline \multirow{5}{*}{5} & Resolution & 3 & 9 & 31.1 & 6 & \multirow{5}{*}{6} \\
\hline & Dynam. HL & 1 & 5 & 8.2 & 6 & \\
\hline & Dynam. SD & 1 & 5 & 17.0 & 5 & \\
\hline & Distortion & 4 & 0 & 20.0 & 2 & \\
\hline & Shutter Speed & 4 & 0 & 20.0 & 1 & \\
\hline \multirow{5}{*}{6} & Resolution & 2 & 10 & 6.4 & 7 & \multirow{5}{*}{7} \\
\hline & Dynam. HL & 0 & 6 & 8.2 & 7 & \\
\hline & Dynam. SD & 0 & 6 & - & 7 & \\
\hline & Distortion & 0 & 4 & 33.3 & 7 & \\
\hline & Shutter Speed & 4 & 0 & 20.0 & 1 & \\
\hline \multirow{5}{*}{7} & Resolution & 10 & 2 & 74.2 & 2 & \multirow{5}{*}{2} \\
\hline & Dynam. HL & 5 & 1 & 3.2 & 3 & \\
\hline & Dynam. SD & 1 & 5 & 15.8 & 6 & \\
\hline & Distortion & 3 & 1 & 20.2 & 5 & \\
\hline & Shutter Speed & 3 & 1 & 33.3 & 7 & \\
\hline \multirow{5}{*}{8} & Resolution & 4 & 8 & 43.9 & 5 & \multirow{5}{*}{4} \\
\hline & Dynam. HL & 5 & 1 & 4.1 & 4 & \\
\hline & Dynam. SD & 2 & 4 & 17.2 & 2 & \\
\hline & Distortion & 2 & 2 & 27.0 & 6 & \\
\hline & Shutter Speed & 4 & 0 & 22.5 & 4 & \\
\hline
\end{tabular}

Total Rank: a camera would rank higher with more data which were better than or equal to their thresholds. 
Table 10. Camera performance in five metrics (maximum, median and minimum).

\begin{tabular}{ccccc}
\hline Metric & Unit & Maximum & Median & Minimum \\
\hline Resolution & $\begin{array}{c}\text { Line-Widths per Head } \\
\text { Height (LPHH) }\end{array}$ & 220.3 & 59.6 & 6.4 \\
$\begin{array}{c}\text { Dynamic } \\
\text { Range HL }\end{array}$ & Merged Gray Steps & 8.2 & 2.6 & 0.0 \\
$\begin{array}{c}\text { Dynamic } \\
\text { Range SD }\end{array}$ & $\begin{array}{c}\text { Recognizable Gray } \\
\text { Steps }\end{array}$ & 18.7 & 17.1 & 14.6 \\
$\begin{array}{c}\text { Lens } \\
\text { Distortion }\end{array}$ & \% & 33.5 & 19.6 & 7.5 \\
Shutter Speed & Milli-Seconds & 40.0 & 25.0 & 20.0 \\
\hline
\end{tabular}

the highlight and shadow dynamic range metrics. Camera $\mathrm{C} 1$ also had the highest rank in lens distortion. Cameras C5 and C6, both with a single VGA image sensor, had the highest rank in shutter speed metric. In total performance ranking, the more the camera data were better than or equal to the thresholds, the higher the overall camera performance rank (Table 9). Camera $\mathrm{C} 1$ had the highest total performance rank.

\subsection{Waterproof Test}

After six flash memory cards, three in Compact Flash (CF) form factor and three in Secure Digital (SD) form factor, were submerged on the bottom of a fresh water pipe at 5 meters in depth for 72 hours, and dried in the air for 48 hours, the video clips stored on all of six cards were able to be recovered.

\subsection{Fire Resistance Test}

The results from the oven tests are shown in Figure 14. There were six oven test curves (inside-chamber temperature versus time) in the figure. In one oven test (temperature curve in purple), the memory media storage chamber was constructed using TIM No. 1. In the other five oven tests, the insulation material used to construct the chamber was TIM No. 2. The fire resistance test method requires that the recording media (flash memory card in these tests) should still be functional after the media, stored inside the chamber, is placed in an oven at $538^{\circ} \mathrm{C}\left(1000^{\circ} \mathrm{F}\right)$ for five minutes. A typical industrial grade memory card cannot be functional if the ambient temperature of the card exceeds $85^{\circ} \mathrm{C}\left(185^{\circ} \mathrm{F}\right)$ [23]. Figure 14 shows that the chamber temperature in all six tests did not exceed $85^{\circ} \mathrm{C}$ in the first five minutes after the chambers were placed into the oven at $538^{\circ} \mathrm{C}\left(1000^{\circ} \mathrm{F}\right)$. During the cool-down time after the chambers were taken out of the oven, the chamber temperature with TIM No. 1 (the temperature curve in purple) raised to a maximum temperature of $138.2^{\circ} \mathrm{C}\left(280.7^{\circ} \mathrm{F}\right)$, exceeding the flash memory card maximum storage temperature of $85^{\circ} \mathrm{C}\left(185^{\circ} \mathrm{F}\right)$. Other chamber temperatures with TIM No. 2 were kept below $85^{\circ} \mathrm{C}\left(185^{\circ} \mathrm{F}\right)$ during the cool-down time with the maximum temperature of $72^{\circ} \mathrm{C}\left(161.6^{\circ} \mathrm{F}\right)$. 


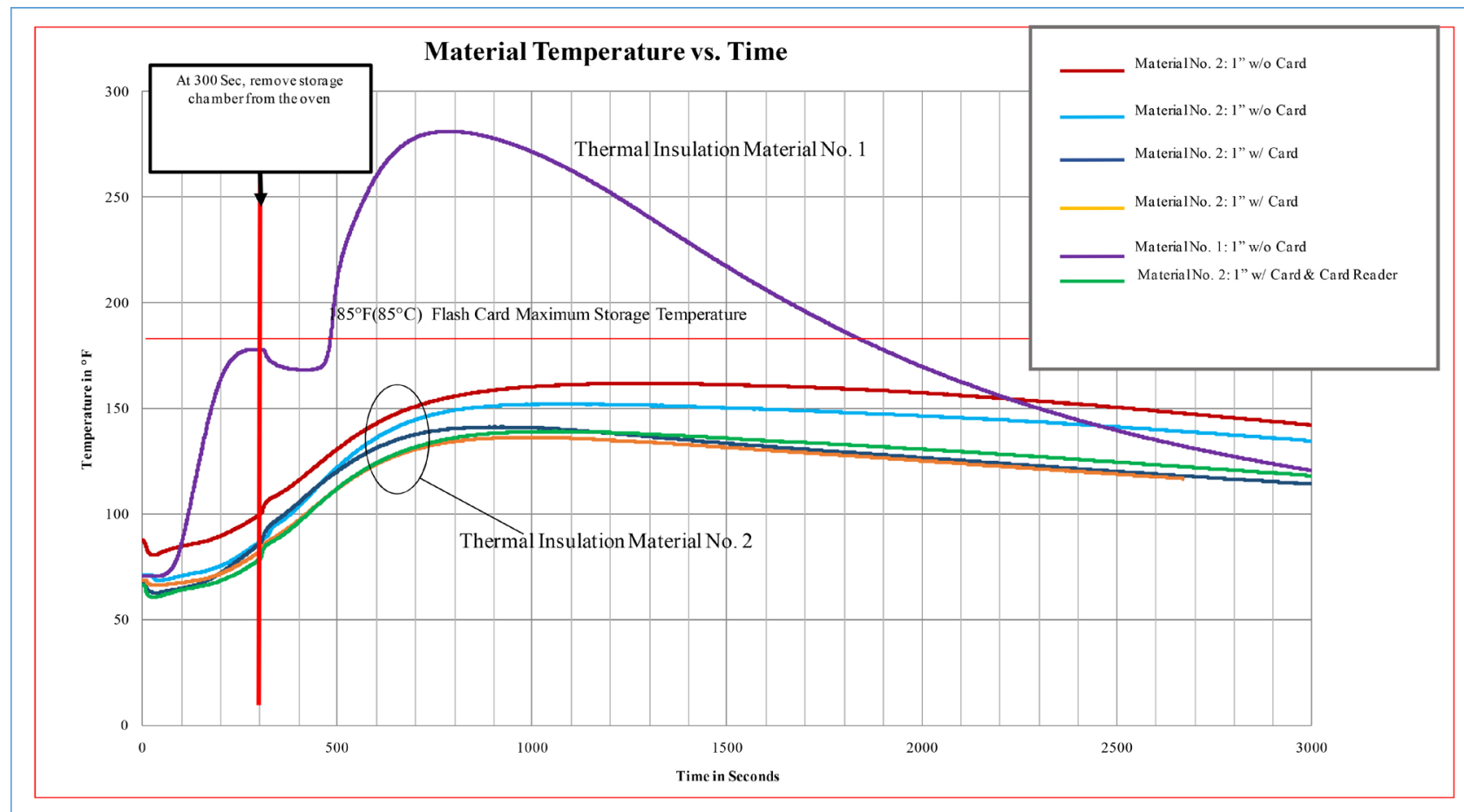

Figure 14. Memory card storage chamber temperature (inside) vs. time.

Among five oven tests using TIM No. 2, the maximum cool-down temperature was higher $\left(72^{\circ} \mathrm{C} / 161.6^{\circ} \mathrm{F}\right)$ as the memory card chamber was empty. The maximum cool-down temperature was lower $\left(59.9^{\circ} \mathrm{C} / 139.8^{\circ} \mathrm{F}\right)$ as a memory card or a memory card reader was inside the memory card chamber. All SD cards, which were placed in a TIM No. 2 storage chamber during the oven test, were able to be read after the tests by a PC with pre-recorded data intact.

\section{Discussion}

\subsection{Photographic Resolution}

The FHD $(1920 \times 1080$ pixels $)$ camera C1 and dual-lens camera C2 $(2 \times 720 \times$ 576 pixels with wide-angle and telephoto lenses) performed well in resolution tests in rear seats. $\mathrm{C} 1$ had $87.5 \%$ of the resolution tests showing results above the resolution thresholds. The HD $(1280 \times 720$ pixels $)$ camera C7 performed worse than the FHD camera with $75 \%$ of rear seat test results above the thresholds. The dual-lens-camera C3 $(2 \times 720 \times 576$ pixels with left/right lenses $)$ had only a 50\% passing-threshold score in rear seat tests. The single-lens VGA $(640 \times 480$ pixels $)$ cameras C5, C6 and C8 failed resolution tests in rear seat images. Single-lens VGA cameras are not suggested for use as security cameras in taxicabs with two or more rows of seats.

The resolution of the images captured by camera C1 in dark (L2) condition (radiated by infrared radiation source) was reduced to $53 \%$ of those captured in daylight (L1) condition. This resolution difference could be attributed to the chromatic aberration of the lenses [24]. The lens focal length varies with differ- 
ent light wavelengths. Cameras C1 and C4 were better focused in visible light, but less focused with infrared radiation; and camera $\mathrm{C} 3$ was the opposite, with better focus under infrared radiation. To solve this problem, the camera lens could be redesigned to reduce chromatic aberration so that the lens focal points in visible light and in infrared radiation are close or even overlap each other. Another solution is to adjust the lens focus to a focal point in the middle of visible light focus and infrared focus. The camera resolutions in visible light and infrared radiation would both be slightly reduced, but the camera resolutions in two light conditions would be relatively balanced.

\subsection{Photographic Dynamic Range}

The camera performance in highlight dynamic range was better than that in shadow dynamic range. In highlight dynamic range tests, in 44 camera/light/seat combination conditions, $26(\sim 59 \%)$ of the camera test data were within the high-light dynamic range thresholds. Most of the failed tests were due to overexposure. In shadow dynamic range tests, in 44 camera/light/seat combination conditions, $10(\sim 23 \%)$ of the camera test data were within shadow dynamic range thresholds. Most of the cameras failed to activate their infrared radiation source in L3 (dark with backlight) in rear-right and/or front right seats. The cameras with infrared radiation sources had a rear-facing light sensor for detecting the daylight condition. The cameras were designed to deactivate the infrared radiation sources in the daylight condition. Under the L3 light condition, the light sensors of seven cameras were confused with the backlight (vehicle headlights), and falsely deactivated the infrared radiation source.

In dynamic range measurements, due to the low resolution of the sample camera image sensors (the imager resolutions varied from $640 \times 480$ pixels to $1920 \times 1080$ pixels) and the long distance between the camera (near the windshield) and the rear seats, the observed pixel count per gray-step-width of the gray scale in the test chart image captured in rear seats varied from 3 to 9 , depending on the camera resolution. The pixel count was much lower than the Imatest Master software recommended (50 pixels per gray-step-width). These low pixel counts per gray-step-width may affect the dynamic range accuracy measured in rear seats.

\subsection{Lens Distortion}

The lens distortion results showed that there was only one camera whose lens barrel distortion exceeded the threshold. The analysis showed that lens distortion was not a challenging issue in these taxicab security camera tests. The lens distortion of most of sample cameras did not affect taxicab facial identification.

\subsection{Camera Shutter Speed}

The shutter speeds of seven out of eight sample cameras met the shutter speed threshold. The shutter speed of one camera was slightly slower than the shutter speed threshold. Along with lens distortion, the camera shutter speed was not a 
challenging issue in these sample taxicab security camera tests.

\subsection{Waterproof Test}

All six Compact Flash (CF) and Security Digital (SD) memory cards passed the 5-meter/72-hour waterproof test in tap-water. However, the taxicab industry in coastal cities regularly deals with saltwater corrosion problems. In order to test the survivability of memory cards in saltwater conditions, a saltwater waterproof test is suggested to submerge memory cards in tap water mixed with $3.5 \%$ of sea salt for 72 hours or longer.

\subsection{Fire Resistance Test}

The simulated memory card storage chamber, built with one heat insulation material (TIM No. 2) with a wall thickness of $2.54 \mathrm{~cm} \mathrm{(1.0"),} \mathrm{was} \mathrm{determined}$ to be able to protect a single memory card from destruction during the $538^{\circ} \mathrm{C}$ $\left(1000^{\circ} \mathrm{F}\right) / 5$-minute fire resistance oven test procedure. The inner temperature of the memory card (or card reader) chambers, made of this heat insulation material, were not higher than $72^{\circ} \mathrm{C}\left(161.6^{\circ} \mathrm{F}\right)$ during the procedure. The maximum cool-down temperature was even lower $\left(59.9^{\circ} \mathrm{C} / 139.8^{\circ} \mathrm{F}\right)$ when a memory card or a memory card reader was inside the memory card chamber. This temperature difference was attributed to the increased thermal capacity by the inserted memory card or memory card reader, which further absorbs the heat and reduces the temperature increase for the same heat input. The initial depression of TIM No. 1 curve at 300 seconds might have been caused by excess moisture in the gluing process or cool air when the oven door was open. The second peak was caused by heat continuing to warm the inside chamber and thermal couple prior to the overall cooling trend. Although the second peak exceeded the flash memory card maximum storage temperature of $85^{\circ} \mathrm{C}\left(185^{\circ} \mathrm{F}\right)$, it should not be inferred that TIM No. 1 is a poor thermal insulation or refractory as this material may work for greater periods of time if thermal mass is added to allow for more heat absorption and longer temperature dwell. It also can be used at higher temperatures, can provide more durability, and can be obtained as a pourable. Multiple factors and materials may be needed to find an adequate design for an adequate fire resistant chamber. This and other materials may work for greater periods of time if thermal mass is added to allow for more heat absorption and longer temperature dwell. Multiple factors and materials may be needed to find an adequate design for a final product.

\subsection{Suggestions for Future Camera Design}

Based on the results of this study:

1) Cameras using FHD $(1920 \times 1080$ pixels $)$ or at least HD $(1280 \times 720$ pixels $)$ image sensors are suggested for effective taxicab facial identification.

2) Camera exposure should be further controlled in daylight (L1) conditions and dark (L2) conditions to avoid image overexposure and underexposure. 
3) Infrared radiation should be uniformly distributed to every cab seat to avoid infrared over exposure or underexposure in dark (L2) and dark with backlight (L3) conditions.

4) The light sensors of the cameras should not face rearward in order to avoid false deactivation of infrared radiation source by following vehicle headlights in dark with blacklight conditions (L3).

\subsection{Suggestions for Consolidated Quality Metric Thresholds}

Currently, the total number of metric thresholds is 57, shown in Table 1. There are multiple thresholds in each of five quality metrics. These multiple thresholds are not convenient for taxicab security camera evaluations. Ideally, these multiple thresholds can be consolidated to one threshold for each quality metric. Statistically, these evaluator-voted thresholds were not normally distributed. Because of these non-normally distributed thresholds, to simplify camera evaluation procedures, the median of the total thresholds in each of the quality metrics is postulated as the consolidated threshold for that metric.

Tables 11-15 show the relationships between the median of the total thresholds and the medians of group thresholds in camera resolution, highlight dynamic range, shadow dynamic range, lens distortion and shutter speed metrics, respectively. The median of group thresholds was defined as the median of a group of thresholds in the same light condition or in the same seat position. The maximum difference between the median of the group thresholds and the median of the total thresholds is $11.7 \%, 20.5 \%, 6.2 \%, 0 \%$ and $10.2 \%$ in camera resolution, highlight dynamic range, shadow dynamic range, lens distortion and shutter speed metrics, respectively. These differences are in a tolerable range, therefore, the median of the total thresholds in each metric is suggested as a consolidated threshold for that metric.

The suggested five consolidated thresholds for five quality metrics are shown in Table 16.

Table 11. Relationship between median of total thresholds and median of group thresholds in resolution metric.

\begin{tabular}{|c|c|c|c|c|c|c|c|}
\hline $\begin{array}{l}\text { Resolution Thresholds } \\
\text { (LPHH) }\end{array}$ & $\begin{array}{l}\text { Daylight } \\
\text { (L1)/Color }\end{array}$ & $\begin{array}{c}\text { Daylight } \\
\text { (L1)/B \& W }\end{array}$ & $\begin{array}{c}\text { Dark } \\
\text { (L2)/B \& W }\end{array}$ & $\begin{array}{c}\text { Dark-BL } \\
\text { (L3)/B \& W }\end{array}$ & $\begin{array}{l}\text { Sunset-RW } \\
\text { (L4)/Color }\end{array}$ & $\begin{array}{l}\text { Sunset-RW } \\
\text { (L4)/B \& W }\end{array}$ & $\begin{array}{l}\text { Median of } \\
\text { Group } \\
\text { Thresholds }\end{array}$ \\
\hline Rear Middle Seat & 61.8 & 59.2 & 75.0 & 40.3 & 44.9 & 47.3 & 53.2 \\
\hline Rear Right Seat & 47.7 & 47.1 & 46.8 & 42.2 & 45.7 & 74.0 & 46.9 \\
\hline Front Right Seat & 47.8 & 52.4 & 51.8 & 62.0 & 48.6 & 39.5 & 50.2 \\
\hline $\begin{array}{l}\text { Median of Group } \\
\text { Thresholds }\end{array}$ & 47.8 & 52.4 & 51.8 & 42.2 & 45.7 & 47.3 & - \\
\hline $\begin{array}{l}\text { Max. Median of Group } \\
\text { Thresholds }\end{array}$ & 53.2 & \multicolumn{2}{|c|}{$\begin{array}{l}\text { Min. Median of Group } \\
\text { Thresholds }\end{array}$} & 42.2 & \multicolumn{2}{|c|}{ Median of Total Thresholds } & 47.7 \\
\hline \multicolumn{7}{|c|}{ (Max. Median of Group Thresholds-Median of Total Thresholds)/Median of Total Thresholds ${ }^{\star} 100$ (\%) } & 11.5 \\
\hline \multicolumn{7}{|c|}{ (Min. Median of Group Thresholds-Median of Total Thresholds)/Median of Total Thresholds ${ }^{*} 100(\%)$} & -11.7 \\
\hline
\end{tabular}


Table 12. Relationship between median of total thresholds and median of group thresholds in highlight dynamic range metric.

\begin{tabular}{|c|c|c|c|c|c|c|c|}
\hline $\begin{array}{c}\text { Dyn. Range HL } \\
\text { Thresholds (Merged } \\
\text { Gray Steps) }\end{array}$ & $\begin{array}{l}\text { Daylight } \\
\text { (L1)/Color }\end{array}$ & $\begin{array}{l}\text { Daylight } \\
\text { (L1)/B \& W }\end{array}$ & $\begin{array}{c}\text { Dark } \\
\text { (L2)/B \& W }\end{array}$ & $\begin{array}{c}\text { Dark-BL } \\
\text { (L3)/B \& W }\end{array}$ & $\begin{array}{l}\text { Sunset-RW } \\
\text { (L4)/Color }\end{array}$ & $\begin{array}{l}\text { Sunset-RW } \\
\text { (L4)/B \& W }\end{array}$ & $\begin{array}{c}\text { Median of } \\
\text { Group } \\
\text { Thresholds }\end{array}$ \\
\hline Rear Middle Seat & 5.7 & 4.6 & 4.2 & 3.3 & 5.5 & 5.7 & 5.1 \\
\hline Rear Right Seat & 6.3 & 5.3 & 3.2 & 4.2 & 6.2 & 4.2 & 4.8 \\
\hline Front Right Seat & 5.1 & 4.3 & 4.8 & 4.2 & 4.8 & 3.3 & 4.5 \\
\hline $\begin{array}{l}\text { Median of Group } \\
\text { Thresholds }\end{array}$ & 5.7 & 4.6 & 4.2 & 4.2 & 5.5 & 4.2 & - \\
\hline $\begin{array}{l}\text { Max. Median of Group } \\
\text { Thresholds }\end{array}$ & 5.7 & $\begin{array}{r}\text { Min. Media } \\
\text { Thres }\end{array}$ & $\begin{array}{l}\text { of Group } \\
\text { olds }\end{array}$ & 4.2 & \multicolumn{2}{|c|}{ Median of Total Thresholds } & 4.7 \\
\hline \multicolumn{7}{|c|}{ (Max. Median of Group Thresholds-Median of Total Thresholds)/Median of Total Thresholds ${ }^{*} 100$ (\%) } & 20.5 \\
\hline \multicolumn{7}{|c|}{ (Min. Median of Group Thresholds-Median of Total Thresholds)/Median of Total Thresholds ${ }^{*} 100$ (\%) } & -10.8 \\
\hline
\end{tabular}

Table 13. Relationship between median of total thresholds and median of group thresholds in shadow dynamic range metric.

\begin{tabular}{|c|c|c|c|c|c|c|c|}
\hline $\begin{array}{c}\text { Dyn. Range SD } \\
\text { Thresholds (Observed } \\
\text { Gray Steps) }\end{array}$ & $\begin{array}{l}\text { Daylight } \\
\text { (L1)/Color }\end{array}$ & $\begin{array}{c}\text { Daylight } \\
\text { (L1)/B \& W }\end{array}$ & $\begin{array}{c}\text { Dark } \\
\text { (L2)/B \& W }\end{array}$ & $\begin{array}{c}\text { Dark-BL } \\
\text { (L3)/B \& W }\end{array}$ & $\begin{array}{l}\text { Sunset-RW } \\
\text { (L4)/Color }\end{array}$ & $\begin{array}{l}\text { Sunset-RW } \\
\text { (L4)/B \& W }\end{array}$ & $\begin{array}{l}\text { Median of } \\
\text { Group } \\
\text { Thresholds }\end{array}$ \\
\hline Rear Middle Seat & 13.8 & 16.8 & 13.2 & - & - & - & 13.8 \\
\hline Rear Right Seat & 12.6 & 18.0 & 17.3 & - & - & - & 17.3 \\
\hline Front Right Seat & 12.1 & 15.0 & 16.3 & - & - & - & 15.0 \\
\hline $\begin{array}{l}\text { Median of Group } \\
\text { Thresholds }\end{array}$ & 12.6 & 16.8 & 16.3 & & & & - \\
\hline $\begin{array}{l}\text { Max. Median of Group } \\
\text { Thresholds }\end{array}$ & 17.3 & $\begin{array}{r}\text { Min. Medi } \\
\text { Thre }\end{array}$ & $\begin{array}{l}\text { of Group } \\
\text { nolds }\end{array}$ & 12.6 & \multicolumn{2}{|c|}{ Median of Total Thresholds } & 15.0 \\
\hline \multicolumn{7}{|c|}{ (Max. Median of Group Thresholds-Median of Total Thresholds)/Median of Total Thresholds ${ }^{*} 100$ (\%) } & 15.2 \\
\hline \multicolumn{7}{|c|}{ (Min. Median of Group Thresholds-Median of Total Thresholds)/Median of Total Thresholds *100 (\%) } & -16.2 \\
\hline
\end{tabular}

Table 14. Relationship between median of total thresholds and max./min. of total thresholds in lens distortion metric.

\begin{tabular}{|c|c|c|c|c|c|c|c|}
\hline $\begin{array}{l}\text { Lens Distortion } \\
\text { Thresholds (\%) }\end{array}$ & $\begin{array}{l}\text { Daylight } \\
\text { (L1)/Color }\end{array}$ & $\begin{array}{l}\text { Daylight } \\
\text { (L1)/B \& W }\end{array}$ & $\begin{array}{c}\text { Dark } \\
\text { (L2)/B \& W }\end{array}$ & $\begin{array}{c}\text { Dark-BL } \\
\text { (L3)/B \& W }\end{array}$ & $\begin{array}{l}\text { Sunset-RW } \\
\text { (L4)/Color }\end{array}$ & $\begin{array}{l}\text { Sunset-RW } \\
\text { (L4)/B \& W }\end{array}$ & $\begin{array}{l}\text { Median of } \\
\text { Group } \\
\text { Thresholds }\end{array}$ \\
\hline Front Right Seat & 24.4 & 24.4 & 24.4 & 24.4 & 24.4 & 24.4 & 24.4 \\
\hline Max. of Total Thresholds & 24.4 & Min. of Tota & Thresholds & 24.4 & \multicolumn{2}{|c|}{ Median of Total Thresholds } & 24.4 \\
\hline \multicolumn{7}{|c|}{ (Max. of Total Thresholds-Median of Total Thresholds)/Median of Total Thresholds ${ }^{*} 100$ (\%) } & 0.0 \\
\hline \multicolumn{7}{|c|}{ (Min. of Total Thresholds-Median of Total Thresholds)/Median of Total Thresholds ${ }^{\star} 100(\%)$} & 0.0 \\
\hline
\end{tabular}

Table 15. Relationship between median of total thresholds and max./min. of total thresholds in shutter speed metric.

\begin{tabular}{|c|c|c|c|c|c|c|c|}
\hline $\begin{array}{l}\text { Shutter Speed Thresholds } \\
\text { (Milliseconds) }\end{array}$ & $\begin{array}{l}\text { Daylight } \\
\text { (L1)/Color }\end{array}$ & $\begin{array}{c}\text { Daylight } \\
\text { (L1)/B \& W }\end{array}$ & $\begin{array}{c}\text { Dark } \\
\text { (L2)/B \& W }\end{array}$ & $\begin{array}{c}\text { Dark-BL } \\
\text { (L3)/B \& W }\end{array}$ & $\begin{array}{l}\text { Sunset-RW } \\
\text { (L4)/Color }\end{array}$ & $\begin{array}{l}\text { Sunset-RW } \\
\text { (L4)/B \& W }\end{array}$ & $\begin{array}{l}\text { Median of } \\
\text { Group } \\
\text { Thresholds }\end{array}$ \\
\hline Rear Middle Seat & 33.3 & 36.7 & 33.3 & 33.3 & 33.3 & 33.3 & 33.3 \\
\hline Max. of Total Thresholds & 36.7 & \multicolumn{2}{|c|}{ Min. of Total Thresholds } & 33.3 & \multicolumn{2}{|c|}{$\begin{array}{l}\text { Median of Total } \\
\text { Thresholds }\end{array}$} & 33.3 \\
\hline \multicolumn{7}{|c|}{ (Max. of Total Thresholds-Median of Total Thresholds)/Median of Total Thresholds ${ }^{\star} 100$ (\%) } & 10.2 \\
\hline \multicolumn{7}{|c|}{ (Min. of Total Thresholds-Median of Total Thresholds)/Median of Total Thresholds ${ }^{*} 100$ (\%) } & 0.0 \\
\hline
\end{tabular}


Table 16. Suggested consolidated metric thresholds (median of total thresholds).

\begin{tabular}{|c|c|c|c|c|}
\hline $\begin{array}{l}\text { Median Thresholds and } 95 \% \\
\text { Confidence Interval }\end{array}$ & Unit & Median & $\begin{array}{c}95 \% \\
\text { Confidence } \\
\text { Interval } \\
\text { (Lower) }\end{array}$ & $\begin{array}{c}95 \% \\
\text { Confidence } \\
\text { Interval } \\
\text { (Upper) }\end{array}$ \\
\hline $\begin{array}{c}\text { Median of } 18 \text { Resolution } \\
\text { Thresholds }\end{array}$ & $\begin{array}{l}\text { Line-Widths per } \\
\text { Head Height* }\end{array}$ & 47.7 & 45.7 & 59.2 \\
\hline $\begin{array}{c}\text { Median of } 18 \text { Dynamic Range } \\
\text { (HL) Thresholds }\end{array}$ & Merged Gray Steps & 4.7 & 4.2 & 5.5 \\
\hline $\begin{array}{c}\text { Median of } 9 \text { Dynamic Range (SD) } \\
\text { Thresholds }\end{array}$ & $\begin{array}{l}\text { Recognizable Gray } \\
\text { Steps }\end{array}$ & 15.0 & 12.6 & 17.3 \\
\hline $\begin{array}{c}\text { Median of } 6 \text { Lens Distortion } \\
\text { Thresholds }\end{array}$ & $\%$ & 24.4 & 24.4 & 24.4 \\
\hline $\begin{array}{c}\text { Median of } 6 \text { Shutter Speed } \\
\text { Thresholds }\end{array}$ & Milliseconds & 33.3 & 33.3 & 36.7 \\
\hline
\end{tabular}

${ }^{*}$ Head Height $=25.5 \mathrm{~cm}$ (Head Height of a 99th Percentile Male).

\section{Conclusion}

The camera tests suggest that single-lens VGA-resolution $(640 \times 480$ pixels $)$ cameras are not appropriate for use as security cameras in taxicabs with two or more rows of seats. To meet resolution requirements in both the visible and infrared conditions, camera manufacturers might either redesign the camera lens to reduce lens chromatic aberration, or adjust the lens focus to a focal point in the middle of visible light focus and infrared radiation focus. Most of the cameras with the light sensor facing rearward falsely deactivated their infrared radiation sources with backlight illumination. Most of the cameras met or exceeded the minimum requirements for lens distortion and shutter speed. The recording memory cards passed the 5-meter/72-hour waterproof tests. The memory card chamber built with one heat insulation material was able to protect an individual memory card during $538^{\circ} \mathrm{C}\left(1000^{\circ} \mathrm{F}\right) / 5$-minute fire resistance oven-test procedure. This camera test protocol could be used by taxi fleets, transportation regulators and/or taxicab security camera manufacturers to ensure that the camera system performance meets the minimum quality requirements for effective in-cab facial identifications. The above camera tests were conducted in a simulated two-row seating taxi-cab. These test results could not be applied to three-row seating taxicabs due to the extended distance from the camera to the third-row seat customers. Since more three-row seating taxicabs are used in taxi industry, additional camera tests are suggested in a simulated three-row seating taxicab.

\section{Impact to Industry}

This research should open discussion among safety professionals and design engineers for consideration of appropriate advanced camera techniques for the application in reducing taxicab driver homicide rates. 


\section{Conflicts of Interest}

All authors have no conflicts of interest to declare.

\section{Acknowledgements}

The authors would like to thank Dr. Hongwei Hsiao, Mr. Paul Keane, Dr. Stephen Martin, Mr. Frank Palya, Dr. Christopher Pan and Mr. Timothy Pizatella from NIOSH and Dr. Ian Radbone for their constructive comments on this manuscript.

The authors would also like to thank former NYC Taxi \& Limousine Commissioner/Chair, and now Professor Matthew W. Daus, Esq, who is the President of the International Association of Transportation Regulators (IATR) and a Distinguished Lecturer at the City University of New York's United States Department of Transportation's Research Center at The City College of New York (Region 2), for his support of this project and arrangement of IATR stakeholder review of the manuscript. In addition, the authors would like to thank the IATR's Board of Directors who facilitated and provided constructive input and comments on the study, including IATR Board Chair Jim Ney of the Philadelphia Parking Authority and Kyle Cockream of Hillsborough County, Florida.

\section{Disclaimers}

The findings and conclusions in this report are those of the authors and do not necessarily represent the views of the National Institute for Occupational Safety and Health. Mention of company names or products does not imply endorsement by the National Institute for Occupational Safety and Health. In addition, citations to websites external to NIOSH do not constitute NIOSH endorsement of the sponsoring organizations or their programs or products. Furthermore, NIOSH is not responsible for the content of these websites. All web addresses referenced in this document were accessible as of the publication date.

The IATR supports this independent and objective research, but does not take a specific policy position or opinion on the findings. These findings will be considered as the IATR continues its work on developing model regulations and best practices for driver safety improvements in the regulatory arena.

\section{References}

[1] NIOSH (2001) Fatal Injuries to Civilian Workers in the United States, 1980-1995. DHHS (NIOSH) Pub. No. 2001-129S.

[2] U.S. Bureau of Labor Statistics (2016) 2014 Census of Fatal Occupational Injuries, Table A-6. Fatal Occupational Injuries Resulting from Transportation Incidents and Homicides by Occupation, All United States. U.S. Bureau of Labor Statistics. http://www.bls.gov/iif/oshwc/cfoi/cftb0291.pdf

[3] U.S. Bureau of Labor Statistics (2016) 2014 Labor Force Statistics from the Current Population Survey, Household Data Annual Averages, 18. Employed Persons by Detailed Industry, Sex, Race, and Hispanic or Latino Ethnicity. U.S. Bureau of Labor Statistics. http://www.bls.gov/cps/aa2014/cpsaat18.pdf 
[4] Menéndez, C.C. (2012) Taxicab Driver Safety. Proceedings of International Association of Transportation Regulators, 2012 Conference, Washington DC, November 2012, 15-17.

[5] Government of Tasmania (2004) Taxi Industry Amendment (Security Cameras) Regulations. Government of Tasmania, Tasmania, Australia. http://www.austlii.edu.au/au/legis/tas/num_reg/tiacr20042004n21609/s5.html

[6] Government of Queensland (2006) Queensland Taxi Security Camera Specifications. Government of Queensland, Queensland, Australia.

[7] Government of New South Wales (2007) NSW Taxi Driver Guide to a Safer Workplace. Government of New South Wales, New South Wales, Australia.

[8] Government of Victoria (2001) Victorian Taxi-Cabs Security Camera Specifications. Government of Victoria, Victoria, Australia.

[9] Taxi \& Limousine Commission of New York (2000) Taxi Cab Notes 4.23.2000 v1.b. Taxi \& Limousine Commission (New York, NY, USA) March 2000 Press Release, Industry Notice \#00-08. Taxi \& Limousine Commission of New York, New York.

[10] Government of Portland (2003) Working Draft, Camera Needs and Wants Matrix Prescriptive Specification. Government of Portland, Portland, Oregon, 17 October 2003.

[11] Government of New South Wales (2007) Taxi Industry Safety and Security Taskforce Final Report. Government of New South Wales, New South Wales, Australia.

[12] Harries, L. and Kozubal, J. (2004) Camera Effective in Reducing Taxicab Crime. Proceedings of the 17 th Annual International Conference of the International Association of Transportation Regulators, Charleston, September 2004.

[13] Ramzan, S. and Christian, A. (2007) Report of the Sheffield Taxi Safety Camera Pilot Study. Sheffield Taxi Camera Safety Project, Sheffield City Council. Sheffield, UK, February 2007.

https://www.whatdotheyknow.com/request/149947/response/369138/attach/3/1\%20 Report\%20Draft\%20V10.pdf

[14] Zeng, S., Amandus, H.E., Amendola, A.A., Newbrau, B.H., Cantis, D.M. and Weaver, D. (2014) Minimum Requirements for Taxicab Security Cameras. Journal of Transportation Technologies, 4, 216-255. https://doi.org/10.4236/jtts.2014.43022

[15] Human Factors Standardization Subtag (2000) Human Engineering Design Data Digest. Human Factors Engineering Technical Advisory Group, Department of Defense, USA, April 2000.

http://www.acq.osd.mil/rd/hptb/hfetag/products/documents/HE_Design_Data_Dig est.pdf

[16] Bockaert, V. (2009) The 123 of Digital Imaging Interactive Learning Suite. Understanding Digital Imaging (DI), Version 5.0, Chapter 1.

[17] Butler, R. (2009) Nikon D5000 Review. Digital Photography Review, 18 June 2009. http://www.dpreview.com/reviews/nikond5000/page18.asp

[18] Imatest (2016) Sharpness: What Is It and How Is It Measured. Imatest, LLC. http://www.imatest.com/docs/sharpness/

[19] Imatest (2016) Using Stepchart. Imatest, LLC. http://www.imatest.com/docs/stepchart/

[20] Imatest (2016) Distortion. Imatest, LLC. http://www.imatest.com/docs/distortion/

[21] ASTM E119-15 (2007) Standard Test Methods for Fire Tests of Building Construc- 
tion and Materials. American Society for Testing and Materials (ASTM), Book of Standards Volume: 04.07, February 2007.

[22] UL 72 (2015) Standard for Tests for Fire Resistance of Record Protection Equipment, Edition Number 16. Underwriters Laboratories (UL), 7 April 2015.

[23] Delkin Devices (2015) Industrial Secure Digital (SD/SDHC) Memory. Delkin Devices.

http://delkinoem.com/secure-digital-industrial.html?gclid=CLWlq7qhpsQCFYYkg QodMkQA8g

[24] Marimont, D.H. and Wandell, B.A. (1994) Matching Color Images: The Effects of Axial Chromatic Aberration. Journal of the Optical Society of America A, 11, 3113-3122.

http://white.stanford.edu/ brian/papers/color/MarimontWandell1994.pdf 